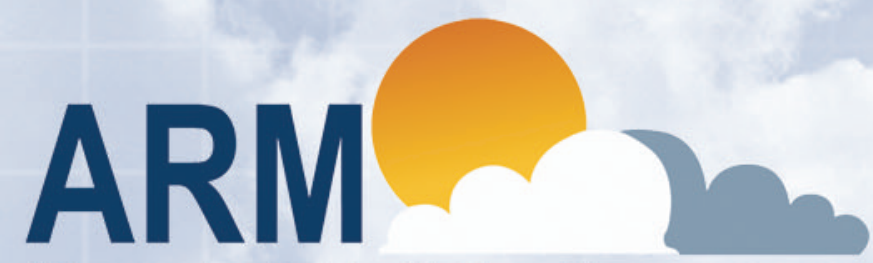

Atmospheric Radiation Measurement

\title{
Atmospheric Radiation Measurement Program Science Plan
}

Current Status and Future Directions of the ARM Science Program

\section{October 2004}




\section{Atmospheric Radiation Measurement Program Science Plan}

\section{Current Status and Future Directions of the ARM Science Program}

Thomas P. Ackerman, Lead Author

Anthony D. Del Genio

Robert G. Ellingson

Richard A. Ferrare

Steve A. Klein

October 2004

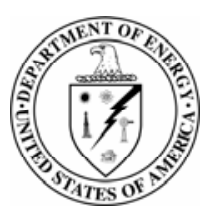

United States Department of Energy

Office of Science, Office of Biological and Environmental Research
Gregory M. McFarquhar

Peter J. Lamb

Charles N. Long

Johannes Verlinde 


\section{Executive Summary}

The Atmospheric Radiation Measurement (ARM) Program has matured into one of the key programs in the U.S. Climate Change Science Program. The ARM Program has achieved considerable scientific success in a broad range of activities, including site and instrument development, atmospheric radiative transfer, aerosol science, determination of cloud properties, cloud modeling, and cloud parameterization testing and development. The focus of ARM science has naturally shifted during the last few years to an increasing emphasis on modeling and parameterization studies to take advantage of the long time series of data now available.

During the next 5 years, the principal focus of the ARM science program will be to:

- Maintain the data record at the fixed ARM sites for at least the next five years.

- Improve significantly our understanding of and ability to parameterize the 3-D cloud-radiation problem at scales from the local atmospheric column to the global climate model (GCM) grid square.

- Continue developing techniques to retrieve the properties of all clouds, with a special focus on ice clouds and mixed-phase clouds.

- Develop a focused research effort on the indirect aerosol problem that spans observations, physical models, and climate model parameterizations.

- Implement and evaluate an operational methodology to calculate broad-band heating rates in the atmospheric columns at the ARM sites.

- Develop and implement methodologies to use ARM data more effectively to test atmospheric models, both at the cloud-resolving model scale and the GCM scale.

- Use these methodologies to diagnose cloud parameterization performance and then refine these parameterizations to improve the accuracy of climate model simulations.

In addition, the ARM Program is actively developing a new ARM Mobile Facility (AMF) that will be available for short deployments (several months to a year or more) in climatically important regions. The AMF will have much of the same instrumentation as the remote facilities at ARM's Tropical Western Pacific and the North Slope of Alaska sites. Over time, this new facility will extend ARM science to a much broader range of conditions for model testing. 


\section{Table of Contents}

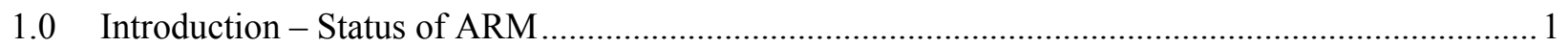

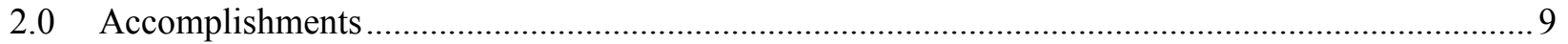

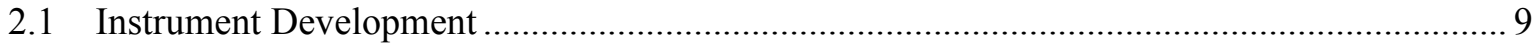

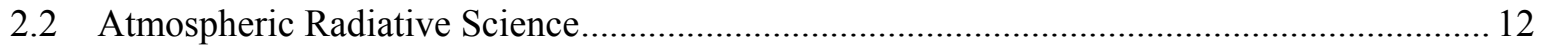

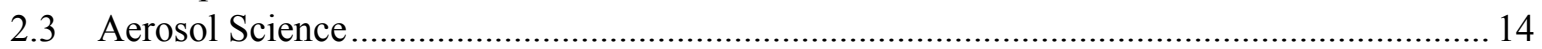

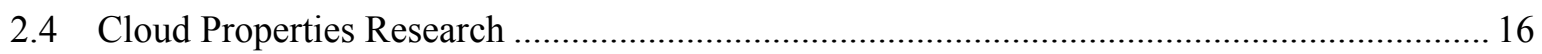

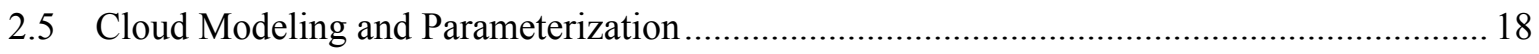

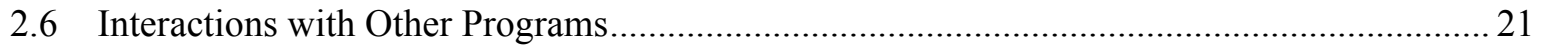

3.0 Cloud and Radiation Physics - Building on past Success.......................................................... 23

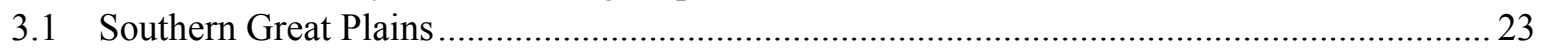

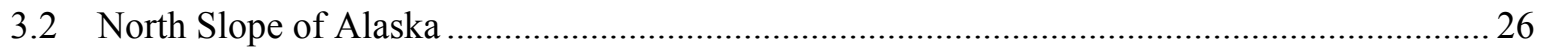

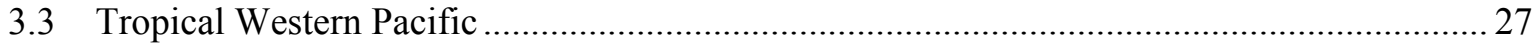

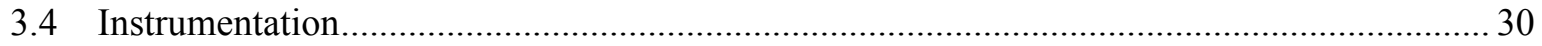

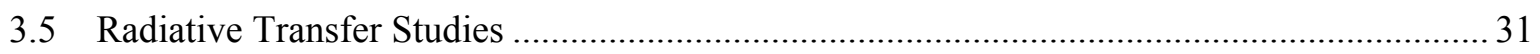

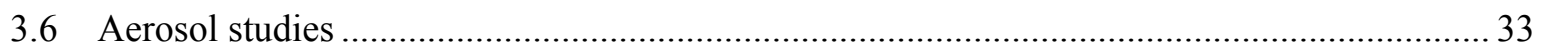

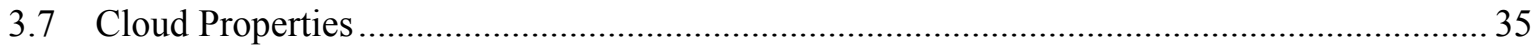

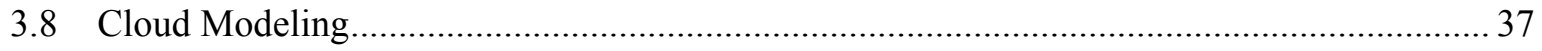

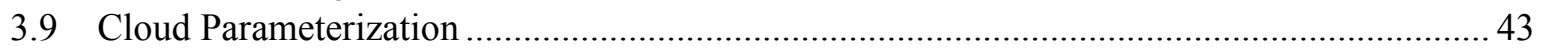

3.10 Using the Multi-scale Modeling Framework ..................................................................... 47

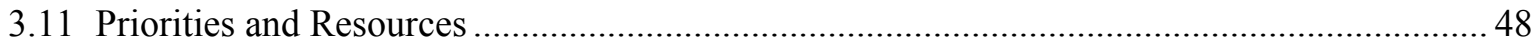

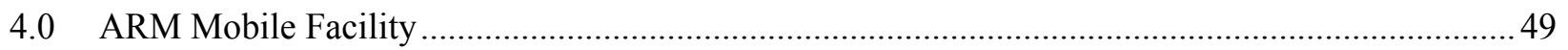

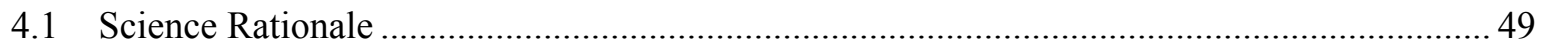

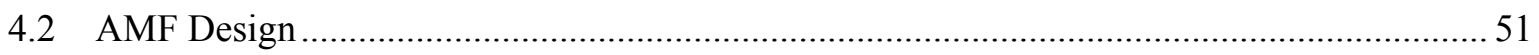

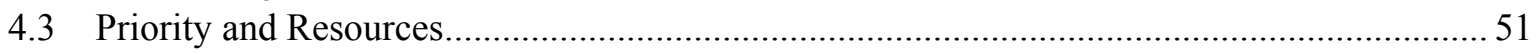

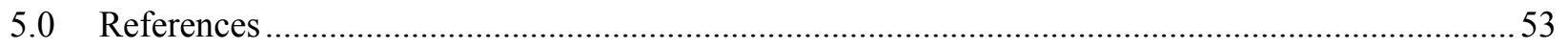




\section{Figures}

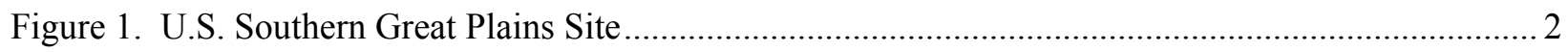

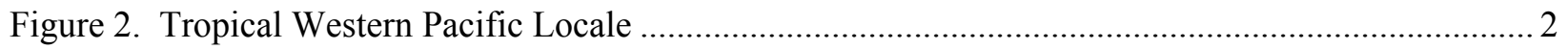

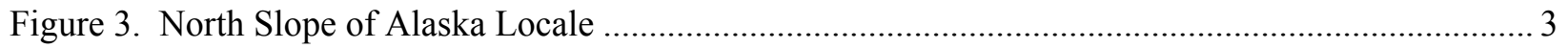

Figure 4. Distribution of Facilities at the Southern Great Plains Site .................................................... 4

Figure 5. Representation of a Single-Column Model from the Southern Great Plains Site....................... 19

Figure 6. Comparison Showing Smaller Moisture and Temperature Errors in Cloud-Resolving Models Versus Single-Column Models (Randall et al. 2003) ............................................... 20

Figure 7. Artist's Rendering of the ARM Mobile Facility ......................................................................... 49 


\section{Acronyms}

ACRF

AERI

AMF

AOT

ARCS

ARESE

ARL

ARSCL

ASP

BBHRP

BOM

CAPT

CCN

CCPP

CCSP

$\mathrm{CP}$

CPM

CRM

ENSO

CGIP

GAPP

GCM

GCSS

GEWEX

HEAT

HIS

IHOP

ISCCP

IWP

LES

LWP

MFR

MFRSR

$\mathrm{MHz}$

MMCR

MMF

M-PACE

MPL

MWR
ARM Climate Research Facility

atmospheric emitted radiance interferometer

ARM Mobile Facility

aerosol optical thickness

Atmospheric Radiation and Cloud Station

ARM Enhanced Shortwave Experiment

Air Resources Laboratory (NOAA)

Active Remotely-Sensed Cloud Locations

Atmospheric Science Program

broadband heating rate profile

(Australian) Bureau of Meteorology

CCPP-ARM Parameterization Testbed

cloud condensation nuclei

Climate Change Prediction Program (DOE)

Climate Change Science Program

Cloud Properties (Working Group)

(ARM) Cloud Parameterization and Modeling

cloud-resolving model

El Nino-Southern Oscillation

GEWEX Continental-Scale International Project

GEWEX Americas Prediction Project

Global Climate Model

GEWEX Cloud System Study

Global Energy and Water Experiment

Houston Environmental Aerosol Thunderstorm (Project)

hemispheric sky imager

International $\mathrm{H}_{2} \mathrm{O}$ Project

International Climatology Program

ice water path

large-eddy simulations

liquid water path

multi-filter radiometer

multi-filter rotating shadowband radiometer

megahertz

millimeter wave cloud radar

Multi-scale Modeling Framework

Mixed-Phase Arctic Cloud Experiment

micropulse lidar

microwave radiometer 
NASA

NOAA

NSA

NWP

PBL

PDF

rms

RUC

SCM

SGP

SHEBA

SST

SWR

TOA

TWP

USDA

VAP

WSI
National Aeronautics and Space Administration

National Oceanic and Atmospheric Administration

North Slope of Alaska

numerical weather prediction

planetary boundary layer

probability distribution function

root mean square

rapid update cycle

single-column model

Southern Great Plains

Surface Heat Budget of the Arctic Ocean

sea-surface temperature

shortwave radiation

top of the atmosphere

Tropical Western Pacific

U.S. Department of Agriculture

value-added product

whole sky imager 


\subsection{Introduction - Status of ARM}

The Atmospheric Radiation Measurement (ARM) Program was initiated by the Department of Energy in FY1989. The original programmatic objectives were to

1. Relate observed radiative fluxes and radiances in the atmosphere, spectrally resolved and as a function of position and time, to the temperature and composition of the atmosphere, specifically including water vapor and clouds, and to surface properties, and sample sufficient variety of situations so as to span a wide range of climatologically relevant possibilities.

2. Develop and test parameterizations that can be used to accurately predict the radiative properties and to model the radiative interactions involving water vapor and clouds within the atmosphere, with the objective of incorporating these parameterizations into global climate models (GCMs).

A few years into the program, Stokes and Schwartz (1994) provided a refined description of ARM's structure and goals. The subsequent ARM science plan, developed in 1996, stated the primary scientific questions as:

1. What are the direct effects of temperature and atmospheric constituents, particularly clouds, water vapor and aerosols on the radiative flow of energy through the atmosphere and across the Earth's surface?

2. What is the nature of the variability of radiation and the radiative properties of the atmosphere on climatically relevant space and time scales?

3. What are the primary interactions among the various dynamic, thermodynamic and radiative processes that determine the radiative properties of an atmospheric column, including clouds and the underlying surface?

4. How do radiative processes interact with dynamical and hydrologic processes to produce cloud feedbacks that regulate climate change?

During its formative years, the program focused on site development, instrument development and procurement, and technique development both in atmospheric retrievals and model evaluation. Rapid and substantive progress in all these areas produced data streams and analyses that translated into new insights into physical processes in the atmosphere and improved modeling of these processes. This in turn fostered evaluations of current climate model parameterizations and development of new parameterizations. As a result, the current ARM Program emphasis is on understanding and modeling fundamental cloud and radiation process and parameterization development and testing for climate models.

The ARM Program's first site, the Southern Great Plains (SGP) site, was established in the early 90s. The SGP site now consists of a central facility near Lamont, Oklahoma, plus four Boundary, three Intermediate, and 23 Extended Facilities scattered over 143,000 square kilometers in Oklahoma and Kansas (Figure 1). ARM's first Tropical Western Pacific (TWP) remote site was installed in 1996 at Manus Island, Papua New Guinea. The second TWP site was installed at Nauru in late 1998 (Figure 2). Operations in the Arctic began with dedication of the Barrow site at the North Slope of Alaska (NSA) in 1997, followed by a year-long participation in the Surface Heat Budget of the Arctic Ocean (SHEBA) experiment in 1998. An additional, less well instrumented remote NSA site was subsequently installed in 
Atqasuk in 1999 (Figure 3). The most recent remote site was installed in Darwin, Australia, in 2002 and is operated jointly with the Australian Bureau of Meteorology. This collection of measurement locales was chosen because it represents three of the main climate regimes around the world.

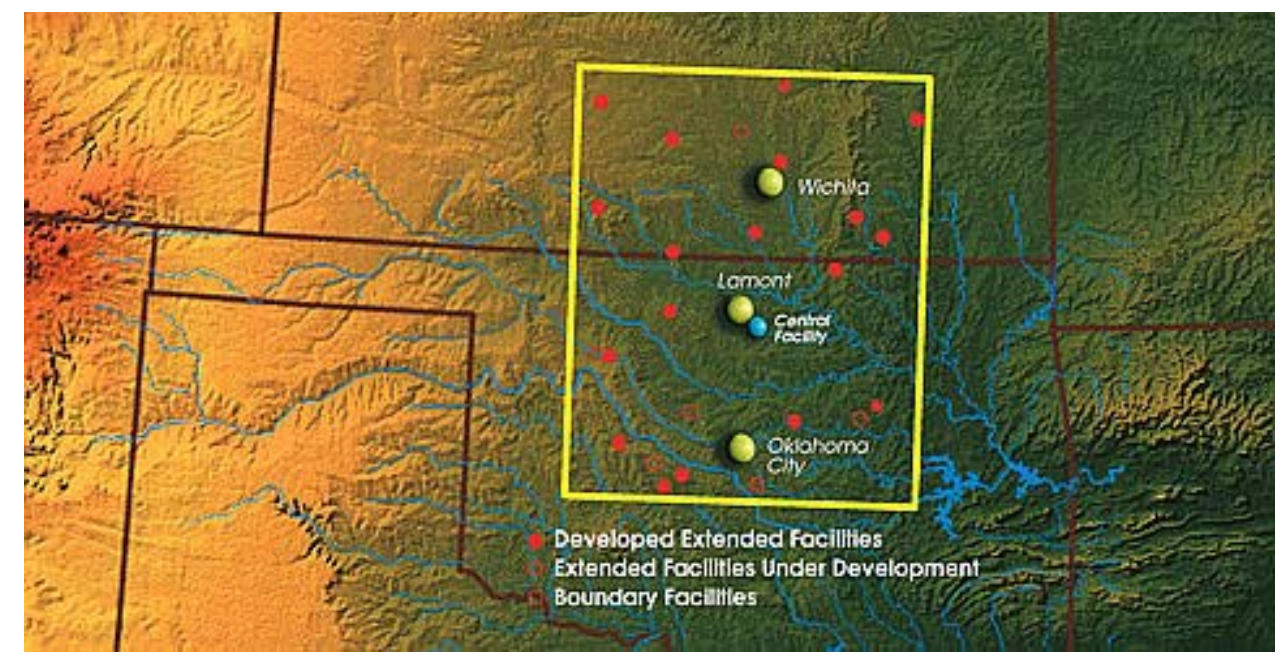

Figure 1. U.S. Southern Great Plains Site

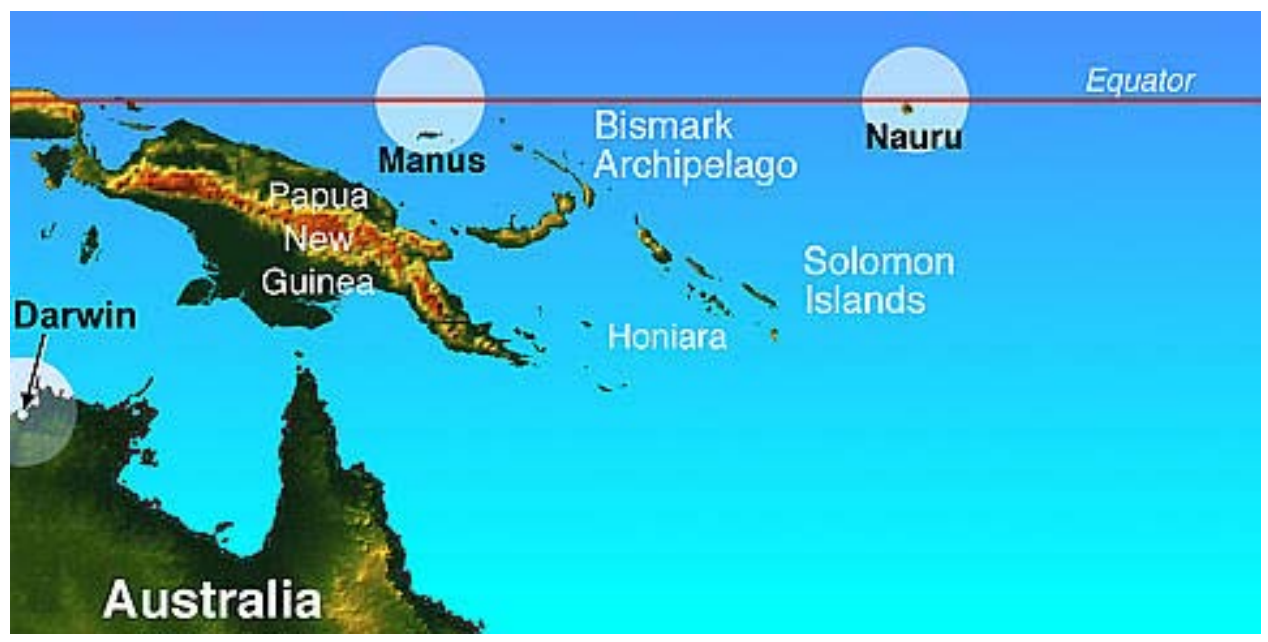

Figure 2. Tropical Western Pacific Locale

The SGP site possesses a unique combination of scientific, logistic, and cooperative advantages. Significant variations in atmospheric temperature, water vapor, and surface heat fluxes can be measured on a yearly, seasonal, or even daily basis. Wide ranges of cloud-forcing meteorological indicators and cloud types are observed in the region on time scales from daily to decadal. The region is easily accessible, relatively inexpensive to operate, and communications and infrastructure are well developed. Cooperative partnerships have evolved with a variety of government laboratories and agencies and also with universities, permitting their collaborative use with ARM of several state-of-the-science radar and climate observing systems and networks. 


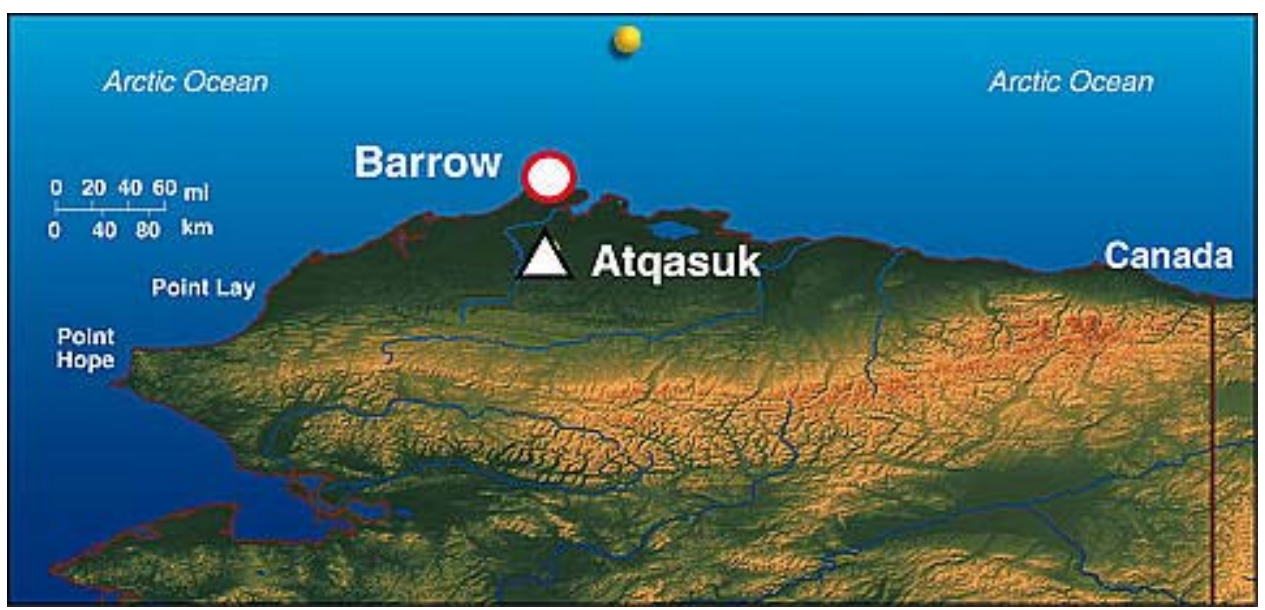

Figure 3. North Slope of Alaska Locale

Facilities located within the SGP site focus on specific scientific issues. A heavily instrumented Central Facility contains a broad array of equipment, ranging from traditional to prototype, for which the advantages of co-location are considerable and remote deployments are not scientifically, economically, or logistically desirable. Instrumentation at the Central Facility provides continuous, detailed, groundbased measurements of the vertical variations of wind speed and direction, water vapor and liquid water, temperature, cloud properties, and radiation. Twenty-three Extended Facilities (Figure 4) distributed over the SGP site provide information on the horizontal variations of clouds, surface radiation budget, and turbulent energy fluxes. On the perimeter of the SGP site, four Boundary Facilities measure the climatically important properties of air entering and leaving the atmospheric column above the site, particularly the transport of water vapor. Three Intermediate Facilities within the SGP site augment the detailed vertical measurements made at the Central Facility.

The SGP site has hosted a wide range of successful Intensive Operational Periods (IOPs) under the sponsorship of ARM and campaigns sponsored by other agencies. By hosting these IOPs and campaigns, the SGP has become fully integrated into all atmospheric science and most other environmental science programs taking place within the SGP domain. As a result, ARM has made important contributions to the efforts of NASA (ground-truth satellite validation), National Oceanic and Atmospheric Administration (NOAA) GEWEX Continental-Scale International Project/GEWEX Americas Prediction Project/Global Energy and Water Experiment (GCIP/GAPP/GEWEX) involvement, soil moisture monitoring, supplementary data for severe weather forecasting), NSF (IHOP experiment), U.S. Department of Agriculture (USDA) (soil moisture monitoring/validation), and other agencies. 


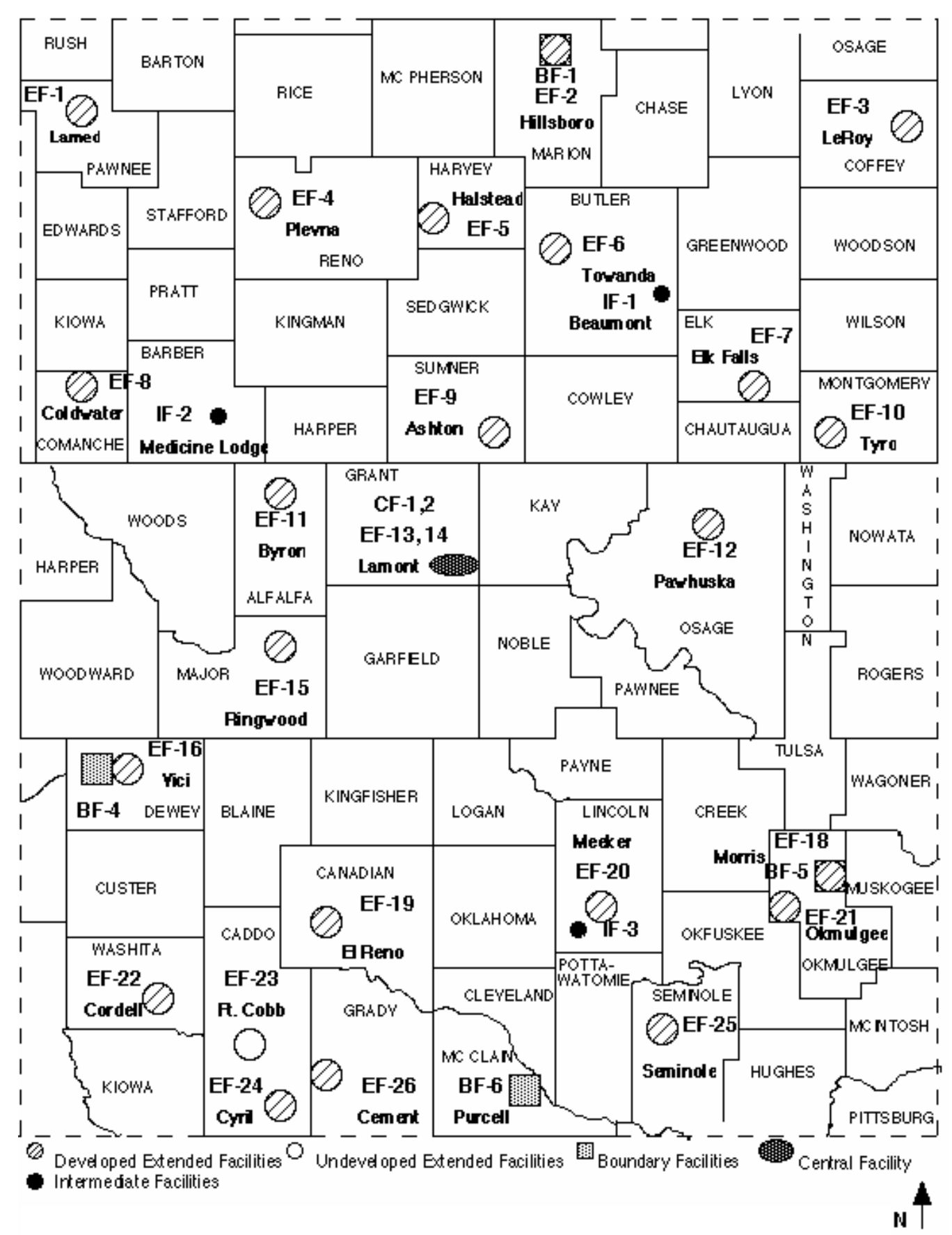

Figure 4. Distribution of Facilities at the Southern Great Plains Site

The NSA locale was chosen as being representative of high latitudes, and because the Arctic is hypothesized to have large climate feedbacks linking surface and tropospheric temperatures, surface albedo, cloud cover, deep ocean water production (the global thermohaline ocean circulation pump), and the polar atmospheric heat sink. In recent decades, significant and interrelated atmospheric, oceanic, and terrestrial changes have been occurring in the Arctic. These changes may be due to natural climate variability associated with the Arctic oscillation (Thompson and Wallace 1998) or greenhouse gas- 
induced warming, or, most likely, some combination of the two. To simulate the observed temperature trends over the last century, particularly the rapid warming of the last two decades, climate models have generally had to include a realistic scenario of increasing $\mathrm{CO}_{2}$ forcing. In contrast to models that project a continued temperature increase in the Arctic, a number of studies based on analyses of existing long-term data sets (e.g., Greenland Sea ice, Arctic atmospheric circulation index) project a major temperature decrease in the next few decades as a result of natural variability. The limited quality of the data sets and the substantive differences among model simulations, however, suggest that neither of these results is conclusive. These contradictory projections from models and observations point to the critical need for high-quality data sets to improve our understanding of the physical processes driving the Arctic regional climate, especially because this region is a critical component of the climate system.

The primary problems confronting the arctic science community demand a system approach, the scope of which requires observations well beyond what ARM can provide. However, the focus of ARM on the measurement of clouds and their impact on radiative transfer is central to many of the feedback questions confounding the community. The NSA sites are collocated with several other research sites, such as the NOAA Climate Monitoring and Diagnostics Laboratory site in Barrow, and the AmeriFlux sites at both Barrow and Atqasuk. The collective presence of these sites makes the locale an attractive option for shorter, more intense observation periods sponsored by a variety of national and international agencies. Both the scope of the problem and the importance of the locale dictate that ARM should collaborate with other programs to reach our goals, with ARM's contribution to such collaborations focusing on the core ARM objectives of developing parameterizations for radiative transfer through a cloudy/clear atmosphere.

The TWP locale was identified in the early days of the ARM Program as its highest scientific priority for a site outside the United States. Convection in the TWP is strongly influenced by the El Nino - Southern Oscillation (ENSO) cycle and has well defined teleconnections to weather patterns in the northern midlatitudes. Because meteorology in the TWP has strong longitudinal gradients, ARM decided to install multiple remote sensing sites along the equator. The site at Manus Island was selected as representative of the convectively active end of the Walker circulation. It is located in the heart of the warm pool and is heavily influenced by the maritime continent geography, particularly the highlands of New Guinea some $200 \mathrm{~km}$ to the south. A second site was located at Nauru, a small equatorial island located at $167 \mathrm{E}$ longitude. The area encompassing Nauru shows the highest climatic variability in outgoing longwave radiation in the world. Intra-annual variability is driven by twice-yearly crossings of the intertropical convergence zone, while interannual variability is strongly coupled with the ENSO cycle. Both sites contain a complete suite of ground-based instruments including lidar, radar, sounding systems, and a full set of radiometers. The original plan included a third site located at Christmas Island (south of Hawaii), representing the subsiding branch of the Walker circulation. Plans for this site were abandoned due to resource limitations and serious logistical problems. More recently, ARM has constructed a third site at Darwin, Australia. This facility is a collaborative effort between ARM and the Australian Bureau of Meteorology. Meteorology at Darwin has a distinct annual cycle that swings from very dry in the austral winter through isolated, very deep convection in the austral spring, to a full monsoon in the austral summer.

Taken in combination, the three TWP sites are a unique asset to ARM and to the world's scientific community. The Manus and Nauru sites are the only long-term and reliable sounding and surface measurement sites in the TWP outside Australia. The climatologies of tropical cloud properties being developed at these sites provide an unprecedented opportunity for physical process research, model 
testing, and satellite validation. For example, analyses have quantified the magnitude, variability, and frequency of cloud occurrence with height, surface radiative energy budget, atmospheric temperature and humidity profiles, and column liquid and water vapor amounts. Data from the TWP sites are used extensively by many scientists interested in both climate and weather. Not unexpectedly, however, success in the TWP comes at a high cost. A combination of distant location and difficult logistics has produced frequent disruptions in data records and higher operational costs than anticipated.

Over the decade of its existence, the ARM science team has become collectively a major contributor to radiation and cloud research. ARM research scientists have made significant contributions in radiative transfer, cloud physics, model development (on a variety of different scales), and climate modeling. While numbers are an uncertain indicator of program accomplishment, they do provide some indication of success. ARM-sponsored investigators now publish about 150 referred journal articles per year. In addition, ARM data are used in many other published studies. In the last several radiation conferences sponsored by the American Meteorological Society, ARM-related abstracts accounted for more than 25\% of the total number. The annual ARM Science Team Meeting attracts 250 to 300 attendees and more than 200 posters representing science projects. ARM science has provided significant advances in almost all areas of atmospheric radiation and many areas of cloud research.

The ARM Program has grown to become a major force in both the national and international arena of atmospheric science. For example, NASA relies heavily on ARM sites for a broad range of satellite validation activities. Both the National Centers for Environmental Prediction (NCEP) and the European Centre for Medium-Range Numerical Weather Forecasts (ECMWF) make extensive use of the data for improvement of their weather forecasting models. Programs of the GEWEX, which operates under the auspices of the World Climate Research Program, make extensive use of ARM data and facilities (Leese et al. 2003). The SGP site was a major contribution to the GEWEX study of the hydrology of the Mississippi River basin. The GEWEX Cloud System Study (GCSS) working groups sponsor a variety of cloud model comparison studies that rely on ARM data for model initialization and evaluation. The ARM sites are also serving as the model for the development of several new research sites within the European community. The GEWEX Working Group on Atmospheric Profiling serves as an active coordination body for research at these sites, including the ARM sites.

The successes of the past decade provide a solid basis for the future of ARM as it enters its second decade. The programmatic goals remain the same, although the emphasis has shifted clearly towards the parameterization and modeling. ARM science has made notable inroads on the first three of the four science questions. Our understanding of the effects of atmospheric composition on column radiation has improved tremendously. While there are still important unanswered questions, our understanding of radiative variability and the factors that drive it, particularly on temporal scales, has increased remarkably due to the efforts of ARM. The ARM Program has made and continues to make significant progress in understanding relationships among dynamic, thermodynamic and radiative processes and how they drive cloud formation and life cycle. Determining links between radiation, cloud processes and cloud feedbacks is difficult, but a problem that remains of considerable interest to ARM.

An update to the program status was published by Ackerman and Stokes in 2003. This companion science plan is intended to provide a blueprint for the next five to 10 years of the program. The next chapter provides a brief summary of major program achievements to date. The subsequent two chapters describe our vision of the future of ARM. Our primary goal is to build on and extend the current science 
goals of ARM, taking advantage of the sound foundation that has already been created. We also discuss the development and use of an ARM Mobile Facility (AMF). This facility - for all intents and purposes, a portable ARM site - will allow the ARM Program to extend its capabilities to different climatic regimes and promote interaction with other research programs. 


\subsection{Accomplishments}

The conceptual foundation of the ARM program is the use of continuous ground-based measurements of the atmosphere to understand cloud life cycle and properties and the interaction between clouds and radiative fluxes. Translating this concept into reality has been a challenging task and has produced considerable progress in atmospheric instrumentation. The first section below highlights some of the major ARM accomplishments in this arena.

Almost from its inception, the principal organizational structure within the ARM science team has been the working group. These working groups are focused around sub-disciplines and have provided a forum for ARM scientists to shape program direction and collaborate with each other. The standing working groups are:

- Aerosols

- Cloud Modeling and Parameterization

- Cloud Properties

- Instantaneous Radiative Flux.

Subsequent sections of this chapter highlight science accomplishments that are organized around these working groups. Some of these accomplishments, however, show blurring of the working group boundaries. The current maturity of the program is tending to further dissolve some of the boundaries between the working groups, which we see as an indication of healthy growth within the science program.

\subsection{Instrument Development}

The genesis of the ARM Program was the fundamentally new idea that ground-based observations of an atmospheric column could be carried out continuously and simultaneously with a suite of passive and active sensors. A corollary was that these measurements could be combined in multiple ways to provide knowledge of atmospheric composition and properties, particularly those relating to clouds and the interaction of clouds with atmospheric radiation. At its inception, most of the active sensors and many of the passive sensors needed to carry out this effort were strictly research instruments and, in many cases, inadequately understood and calibrated. The ARM Program has had a significant impact on atmospheric instrumentation during the past decade, such as

- developed an operational version of a millimeter cloud radar and collected the first multi-year data sets

- developed the first operational version of a Raman lidar

- developed the first operation version of an infrared interferometer using electronic coolers rather than cryogens

- improved significantly the performance of 2-channel microwave radiometers

- improved existing and aided in the development of new sky imagers.

Millimeter Cloud Radar: Clouds modulate both the amount of incoming solar radiation that reaches the Earth's surface and the amount of terrestrial radiation that escapes into space. They also directly alter 
atmospheric heating rates. The magnitude of these impacts is a result of the location and composition of the clouds. The key ARM instrument for the measurement of cloud properties is the millimeter cloud radar (MMCR; Moran et al. 1998). The first operational MMCR was deployed at the SGP in 1996; the ARM Program now operates five MMCRs at its sites around the world. They are highly sensitive, wellcalibrated systems that operate at specific wavelengths designed to detect cloud droplets and ice crystals. Data from these MMCRs, as well as other ARM sensors, are combined to produce a comprehensive survey of cloud location, cloud reflectivity, and cloud droplet velocity at 10 -second intervals above the ARM sites (Clothiaux et al. 2000). Cloud liquid and ice water content profiles, as well as information about the size and shape of the constituent cloud particles, are subsequently derived from these data using specialized algorithms (e.g., Dong et al. 2000; Mace et al. 2002). This information has been used to test radiative transfer codes and to understand how specific atmospheric processes impact the radiative characteristics of clouds. These data sets provide long-term statistics of the location and particle characteristics of clouds at the ARM sites and reveal new information about the relationship between cloud structure and the thermodynamic state of the atmosphere (Mace et al. 2001).

Through the ARM effort in developing the MMCR and using the data stream, these instruments are now recognized as one of the critical instruments in climate research. Continuing advances in MMCR signal processing and radar design, as well as the use of additional MMCR wavelengths, will soon permit the development of more advanced algorithms to determine cloud properties, which will in turn drive new research.

Raman Lidar: Water vapor is the most dynamic and radiatively active gas in the atmosphere. Accurate profiles of this constituent are critical for the ARM Program. The ARM Raman lidar is the first and only autonomous Raman lidar providing diurnal water vapor profiles throughout the boundary layer and up to the tropopause at night (Goldsmith et al. 1998). This instrument has played a critical role in ARM water vapor IOPs, serving as a transfer standard between profiling observations and measurements of water vapor column amount (Revercomb et al. 2003). The Raman lidar also measures profiles of aerosol extinction and backscatter, as well as linear depolarization ratio. Seasonal averages of the aerosol profiles as a function of aerosol optical thickness, airmass origin, and other properties have been published (e.g., Turner et al. 2001; Ferrare et al. 2001). The polarization sensitivity, coupled with the direct measurements of aerosol extinction and upper tropospheric humidity at night, is leading to new insights on cirrus cloud properties. Together with measurements of cloud liquid water by the microwave radiometer, Raman lidar observations are also being used to study at the aerosol indirect effect by providing observations of aerosols and water vapor near cloud boundaries.

Atmospheric Emitted Radiance Interferometer: Comparisons of radiative transfer codes highlighted the need for high-spectral-resolution observations of downwelling radiance to constrain longwave radiative transfer models. The atmospheric emitted radiance interferometer (AERI) was developed as part of the ARM Program to address this need. The AERI observes downwelling radiance from 530-3000 cm-1 (3.3 - $19 \mu \mathrm{m}$ ) at $1 \mathrm{~cm}^{-1}$ resolution. It operates autonomously through the use of a mechanical Stirling cooler that eliminates the need for cryogenic liquids. Well-characterized blackbodies calibrate AERI observations to an absolute accuracy of better than $1 \%$ of the ambient radiance. The ARM Program developed an extended range AERI that operates from 400 to $4000 \mathrm{~cm}^{-1}$ (2.5 to $\left.25 \mu \mathrm{m}\right)$; this additional range makes it suitable for measuring radiances in the part of the atmospheric spectrum between 18 and $25 \mu \mathrm{m}$, which becomes semi-transparent at low water vapor column concentrations. 
AERI data have been used to understand and help characterize water vapor observations at the SGP site (e.g., Turner et al. 2003a), improve water vapor continuum models in the infrared (Tobin et al. 1999; Turner et al. 2003b), and provide routine profiles of water vapor and temperature in the boundary layer (e.g., Feltz et al. 2003). The AERI also plays an important role in the remote sensing of cloud properties. For example, microphysical properties of Arctic mixed-phase clouds have been retrieved from AERI spectra (Turner 2003). The AERI is an important component for many algorithms that use a combined sensor approach to determine microphysical cirrus properties. A new sampling strategy is currently being implemented to increase the temporal resolution of the AERI by an order of magnitude, which will greatly aid in analysis of the AERI observations in dynamic cloud scenes.

Microwave Radiometer: The ARM Program played a crucial role in the advancing the development of the microwave radiometer (MWR) into its current status as a precision measurement standard for column water vapor amount and liquid water path. While commercial instruments were newly available at the onset of the ARM program, MWR measurements of column water vapor were calibrated by radiosonde ascents. ARM scientists aided in subsequent instrument design, developing instrument calibration protocols, and refining retrieval algorithms so that now radiosonde profiles are calibrated by MWR measurements of column water vapor amount. This role reversal is the result of a decade-long collaboration among ARM, private companies and other government laboratories.

Sky Imagers: Measuring cloud fraction is one of the fundamental measurements required by the ARM Program. At the outset of the program, no commercial instrument was available to provide this information. Sky coverage was generally determined by periodic human observations or time series analysis of vertically pointed instruments. Neither method was deemed optimal. To fill this need, the ARM Program supported the further development of a whole sky imager (WSI), which was originally developed for military applications. The WSI measures hemispheric, calibrated sky radiances. These radiances are used to compute cloud cover and can also be used for direct comparison with radiative transfer models. Also, by taking advantage of the large dynamic sensitivity range of the WSI detector, an algorithm was developed to estimate cloud cover at night by using either moonlight or examining whether or not about 100 of the brightest magnitude stars are occluded by cloud.

More recently, inexpensive digital cameras have become widely available. This led to the development of a prototype hemispheric sky imager (HSI), cooperatively financed by ARM and the NOAA/Air Resources Laboratory Surface Radiation Research Branch. Whereas the WSI is intended as a sophisticated sky radiance measurement system, the HSI was developed as a cost-effective alternative targeted specifically at estimating daylight-only fractional sky cover. An inexpensive, commercially available instrument, the total sky imager (TSI), followed from the prototype design. Taking advantage of advancements in digital photographic systems, the TSI can produce sky cover retrievals at a rapid 30second resolution. Comparison studies show that the retrieved daylight sky cover estimates from the WSI and TSI agree within $+/-5 \%$ sky cover $87 \%$ of the time, and within $+/-10 \%$ sky cover over $97 \%$ of the time (http://www.arm.gov/docs/documents/tech_reports/arm-tr-006.pdf).

The ARM Program has played an important role in refining other instruments and measurement techniques as well. These include, for example, participation in the development of the micro-pulse lidar, improving the understanding of atmospheric spectroscopy both theoretically and observationally, and advancing the measurement of diffuse solar radiation. Also, because side-by-side comparisons and calibration techniques are critical to instrument understanding, the ARM Program has sponsored and 
hosted at its sites a number of campaigns focused on these issues. The ARM Program has also funded the development of a broad range of retrieval techniques using single and multiple data streams. A number of the more important advances in this area are described in the following sections.

\subsection{Atmospheric Radiative Science}

The overall programmatic objective of the instantaneous radiative flux (IRF) Working Group scientific studies is to develop and test radiation parameterizations at the accuracy required for climate studies. Initially, the IRF Working Group concentrated its activity on clear-sky, longwave (wavelengths $>4 \mu \mathrm{m}$ ) radiation problems, primarily because the instrumentation to attack these problems was readily available. Also, routine observations of clouds and shortwave radiation were not yet at the level of sophistication necessary for significant advances on shortwave and the more general cloud-radiation objectives. During the last few years there has been a steady migration from the longwave to the shortwave and from clear to cloudy-sky problems as new instrumentation has become available and as unexplained, climatically significant anomalies between observed and model-calculated quantities have been reported.

The most significant achievements by the IRF Working Group to date are:

- demonstrated agreement between theory and measurement in clear sky downwelling longwave and shortwave flux at the surface at a level of 5 to $10 \mathrm{~W} \mathrm{~m}^{-2}$ root mean square (RMS) for midlatitude conditions by improvements in both diffuse radiometry, longwave models, and measurement of the atmospheric state, particularly water vapor

- resolved to a large degree the anomalous shortwave absorption issue by identifying and reducing major uncertainties in measurement, and modeling and sampling the transport of clear- and cloudy-sky solar radiation

- improved understanding of 3-D radiative transfer

- developed a new approach to the cloud overlap problem for GCMs.

Each of these accomplishments is discussed briefly below. Interested readers are encouraged to pursue the references for further detail. Because radiative transfer is at the core of much of what ARM science does, some of the activities highlighted under the other working groups involved significant participation from this working group.

Clear-Sky Longwave Radiation: Clear-sky longwave radiative transfer appears to be largely a solved problem. Comparisons of high spectral resolution Line-By-Line Radiative Transfer Model calculations with interferometer data from the SGP and TWP sites show that the uncertainty in the calculated longwave flux at the surface is better than $2 \mathrm{~W} \mathrm{~m}^{-2}$ for the range of measured precipitable water vapor values (Turner et al. 2003b). Because there are no major spectral errors in the flux calculation, we expect that model calculations will yield accurate cooling rate profiles in the spectral interval from 4 to $20 \mu \mathrm{m}$. This accomplishment is principally due to refinements in the empirical treatment of the longwave water vapor continuum used in line-by-line models (e.g., Tobin et al. 1999; Mlawer et al. 1999).

Clear-Sky Shortwave Radiation: At the beginning of the ARM Program, the overall accuracy of shortwave radiative transfer models was quite uncertain. Early studies demonstrated that broadband shortwave direct irradiance models and measurements were in agreement to better than $1 \%$, but model calculations of the diffuse flux were typically high by 10 s of percents, sometimes off by as much as 30 
$\mathrm{W} \mathrm{m}^{-2}$ (Halthore et al. 1998; Kato et al. 1997). Additional research results, primarily impacting the actual measurements of diffuse shortwave radiation, have reduced this difference to about $10 \%$ or $7-10 \mathrm{~W} \mathrm{~m}^{-2}$ (Cess et al. 2000; Dutton et al. 2001; Michalsky et al. 1999, 2004; Philipona 2002; Younkin and Long, 2004).

Measurement of Water Vapor: For years, the radiation community has contended that, because water vapor dominates longwave radiative transfer, uncertainty in water vapor observations is the limiting factor in the improvement of longwave models. Through a series of water vapor IOPs and the hard work of many ARM scientists, ARM has developed multiple improvements in methods to measure water vapor. These include developing and improving both instruments and retrieval codes. Based on detailed comparisons among instruments and between measurements and models, the consensus is that ARM is now able to measure water vapor to better than 4\% (Revercomb et al. 2003; Turner et al. 2003a).

Anomalous Shortwave Absorption: The anomalous shortwave absorption debate was ignited by three studies finding that the solar radiation absorbed by clouds is substantially underestimated by models (Cess et al. 1995; Ramanathan et al. 1995; Pilewskie and Valero 1995). In response to these studies, ARM supported a special IOP — the ARM Enhanced Shortwave Experiment (ARESE-I) — in 1995, in the SGP vicinity, to deal exclusively with this problem. Valero et al. (1997) and Zender et al. (1997) found enhanced absorption in ARESE-I, but these results and those of the previous studies were questioned by many different investigators citing the small number of observations for extensive cloud cover, the methodology used to analyze the measurements (Stephens 1996; Barker and Li 1997; Cess et al. 1997; Zhang et al. 1998), the effects of 3-D radiative transfer and sampling (Marshak et al. 1997; Marshak et al. 1999), the potential problems of aerosols ( $\mathrm{Li}$ and Trishchenko, 2001), and potential errors in the observation (Trishchenko and Li 1998; Rapp 2001).

The findings from ARESE-I motivated a second experiment conducted in the spring of 2000. To solve the calibration conundrum resulting from ARESE-I, ARESE-II devoted much effort into instrument calibration and intercomparison (Michalsky et al. 2002). Several sets of spectral and broadband radiometers were deployed and intercompared, and all generally agreed to within $10 \mathrm{Wm}^{-2}$. For the four observed extensive cloud cases, independent investigations (Li et al. 2004; Ackerman et al. 2003) did not find a cloud absorption anomaly close to those found previously, although there remains a small instantaneous discrepancy on the order of $20 \mathrm{Wm}^{-2}$. While one cannot negate an absorption anomaly of much smaller magnitude, if it exists, it should be viewed within the framework of the various uncertainties in the measurements $\left(\sim 10 \mathrm{~W} \mathrm{~m}^{-2}\right)$, the mismatch between ground and aircraft observations $\left(<20 \mathrm{~W} \mathrm{~m}^{-2}\right)$, model calculations $\left(<20 \mathrm{~W} \mathrm{~m}^{-2}\right)$, and errors in input data, particularly the variation of the underlying surface albedo.

3-D Radiative Transfer: Throughout the 1990s, ARM-supported scientists have devoted considerable effort to 3-D radiation transport. The major accomplishments include: (1) increased understanding of transport in 3-D media (e.g., Byrne et al. 1996; Davis and Marshak, 2001; O'Hirok and Gautier 1998), (2) the development of an intercomparison of 3-D radiative transfer methods (I3RC) applied to Earth's atmosphere and (3) a study of how well 1-D solar radiative transfer codes - especially those used in numerical weather prediction (NWP) models and GCMs - interpret and handle unresolved clouds as determined directly by detailed radiation calculations applied to cloud-resolving model (CRM) output (Barker et al. 2003). In general, the various Monte Carlo methods for calculating radiative transport in 3-D media agree well with each other. 1-D models do not, in general, simulate 3-D codes 
well, particularly when considerable horizontal transport results from multiple scattering. Although our understanding of 3-D radiative transport has increased substantially during the past decade, there have been few attempts to validate 3-D radiation models using ARM data (e.g., in the shortwave, Barker and Marshak 2001; Han and Ellingson 2000).

Cloud Overlap: Today's cloud parameterizations tend to predict cloud properties, including cloud fraction, at all model levels. In the calculation of both radiative transfer and precipitation, the individual cloud layers need to be aligned and this alignment affects the outcome of the calculations. The method of aligning individual cloud layers is usually referred to as "cloud overlap." The three most common rules for cloud overlap used in GCMs are maximum, random, and maximum-random overlap. Research in the past several years has refocused on the cloud overlap problem (e.g., Morcrette and Jakob 2000) for a number of reasons. First, the increase in vertical resolution in GCMs may require a rethinking of cloud overlap descriptions. The original application of cloud overlap schemes was to clouds formed by early cloud parameterizations in a very few model layers. Current models have many more layers as well as more complex parameterizations. Second, cloud overlap has been shown not only to affect radiative calculations, but also precipitation process calculations (Jakob and Klein 1999, 2000). Most importantly though, new information on the vertical structure of cloud fields from observations made with groundbased cloud radars (e.g., Mace and Benson-Troth 2002, Hogan and Illingworth 2000, Hogan et al. 2001, Mace et al. 1998) allows an evaluation of the overlap parameterizations currently used in GCMs. Though significant progress has already been made using ARM data (e.g., Mace and Benson-Troth 2002), ARM's suite of ground-based remote sensors at sites around the globe places the program in a unique position to support additional key model developments in this area.

\subsection{Aerosol Science}

Although the objectives of the ARM Program are focused on clouds, it was recognized early in the program that the direct role of aerosols on radiative transfer and their indirect impact on cloud properties needed to be incorporated into the research agenda. The two primary objectives of ARM aerosol research are to: (1) relate observations of radiative fluxes and radiances to the optical properties of atmospheric aerosols, and (2) use these relationships to develop and test parameterizations to predict the atmospheric radiative properties accurately. The first research objective has led the ARM Program to concentrate on measurements that characterize the optical properties of aerosols. Because the indirect effect is such a complicated problem in terms of its physics and chemistry, research in this area has emphasized both observations and modeling. Also, because of the obvious links to radiative transfer and cloud properties, there is considerable overlap with accomplishments in these areas.

Significant accomplishments in ARM aerosol research include:

- provided a data set of long-term, continuous measurements of surface aerosol properties, including the longest available record of aerosol hygroscopic growth factor

- provided a unique data set of vertical profiles of aerosol properties acquired routinely several times per week for more than two years. In conjunction with the surface data permits, this data set permits, for the first time, detailed assessments of the relationship between surface measurements and column properties of aerosols.

- developed a unique, long-term data set of aerosol backscatter to extinction ratio values, which document the large variability in aerosol properties as a function of altitude and time. 
- produced the first ground-based evidence of the indirect effect of aerosols on cloud droplet size in both midlatitudes and the Arctic

- developed a broad range of new physically based model parameterizations for aerosol cloud effects that are being used in studies of the climatic effect of aerosols.

Aerosol Characterization Measurements: Because accurate knowledge of pertinent aerosol properties is required to represent aerosol direct forcing accurately in models, ARM has systematically measured aerosol properties at and above the surface, especially at the SGP site. A key parameter for quantifying how aerosols attenuate the direct solar beam is aerosol optical thickness (AOT). Consequently, ARM has pursued several methods to accurately measure AOT. Comparisons of AOT retrieved by diverse ARM instruments, including the rotating shadowband spectroradiometer (RSS), multifilter rotating shadowband radiometer (MFRSR), Cimel Sun Photometer, and the National Aeronautics and Space Administration (NASA) Ames AATS-6 Sun photometer, agreed to within 0.026 (2 st. dev), which is close to the World Meteorological Organization goal of 0.02 (Schmid et al. 1999). This is the current limit for operational instruments. Aerosol measurements acquired by the surface-based SGP aerosol observing system (AOS) have provided a large data set to study additional aerosol optical properties at the surface. For example, the aerosol hygroscopic growth factor has been measured continuously at the surface since 1999; this represents the longest record of such measurements (Sheridan et al. 2001). This factor is used in models of aerosol radiative forcing to calculate how relative humidity affects aerosol radiative properties. ARM AOS measurements show distinctly different values of hygroscopic growth in the smoke aerosols resulting from local field burning frequently conducted around SGP site. These results will allow models to use more realistic values of hygroscopic growth for biomass-burning aerosols.

In addition to systematically measuring aerosol properties at the surface, ARM has begun characterizing aerosol vertical properties using various techniques. In March 2000, ARM instituted a unique program to routinely (2-3 times/week) measure aerosol scattering and absorption profiles with a light aircraft (Cessna 172) over the SGP site using aerosol measurements similar to those made at the surface. Results from this In situ Aerosol Profiling program indicate that long-term surface aerosol measurements of intensive properties at SGP statistically capture the median column aerosol properties, but may not accurately represent day-to-day variations in the column (Andrews et al. 2001). Vertical variability in aerosol properties has also been investigated using the ARM SGP Raman lidar measurements. Average aerosol and water vapor profiles derived from SGP Raman lidar measurements over two years (1998 and 1999) show significant differences in the vertical variability of aerosols and water vapor. The scale height of aerosol extinction varies considerably as both a function of season and AOT, increasing from less than $1 \mathrm{~km}$ in the winter to over $2 \mathrm{~km}$ during turbid summer days (Turner et al. 2001). Profiles of the aerosol extinction to backscatter ratio ("lidar ratio") derived from SGP Raman lidar measurements acquired in 1998 and 1999 show that large variations in this ratio occurred $30 \%$ of the time. This implies that significant variability in the vertical distribution of the aerosol size distribution, shape, and/or composition often occurs (Ferrare et al. 2001).

Indirect Aerosol Effects: Indirect effects of aerosols (i.e., influence of aerosols on cloud droplet number and cloud albedo) have been recognized as a potentially important mechanism for climate modification for many years, but with only scattered qualitative evidence of the effect and very little quantitative evidence? ARM research has produced progress in both modeling and measurement of indirect effects of aerosol. Aircraft measurements of cloud condensation nuclei (CCN) concentration above the SGP site have been used to evaluate a global aerosol model (Ghan et al. 2001a). Surface measurements have been 
used to retrieve aerosol hygroscopicity (Feingold and Morley, 2003) and to produce the first surfacebased detections of the indirect effect (Feingold et al. 2003; Kim et al. 2003; Penner et al. 2004). By means of radiative transfer modeling and analysis of various satellite and surface observation data sets, $\mathrm{Li}$ and Trishchenko (2001) demonstrated (1) the differences and influential factors of aerosol radiative forcing under clear and cloud conditions and at the top and bottom of the atmosphere; and (2) the contribution of aerosol radiative forcing to cloud radiative forcing. Aerosol forcing is usually larger and more variable at the surface than at the top of the atmosphere (TOA). Therefore, the ratio of cloud radiative forcing (TOA vs. surface) used widely in studying the cloud absorption anomaly is vulnerable to the aerosol effect (systematic bias) (Li and Trishchenko 2001).

Parameterization and Modeling Studies: ARM modelers have developed a physically based droplet nucleation parameterization (Ghan et al. 1993, 1995; Chuang and Penner 1995; Abdul-Razzak et al. 1998; Abdul-Razzak and Ghan 2000, 2002) that expresses droplet nucleation in terms of an arbitrary mixture of a variety of aerosol compounds with variable size distribution. This permits treatment of the competition between various components (natural and anthropogenic) of the aerosol as CCN (Ghan et al. 1998) and the competition between sources and sinks in the droplet number balance (Ghan et al. 1997). Versions of the parameterization are being used to evaluate the forcing by anthropogenic aerosols in the National Center for Atmospheric Research (NCAR) Community Climate Model and Community Atmosphere Model (Ghan et al. 1997, 2001a, b), the Max-Planck Institute ECHAM global climate model (Lohmann et al. 1999, 2000), and the University of Michigan/Lawrence Livermore National Laboratory GRANTOUR model (Chuang and Penner 1995; Chuang et al. 1997, 2002). ARM modelers have developed methods to jointly treat both the indirect effect and the effects of absorption by black carbon in cloud droplets and have evaluated these combined effects in a global model (Penner et al. 2003). Evaluations by ARM modelers have figured prominently in estimates of indirect effects of aerosols reported in the Intergovernmental Panel on Climate Change (IPCC) Third Assessment Report (Penner et al. 2001). ARM modelers have also combined aerosol modeling with satellite analysis to isolate the indirect effect signature in cloud optical depth, droplet number concentration, and droplet size (Harshvardhan et al. 2001, Schwartz et al. 2002). They have also used large eddy simulations of the coupled aerosol-clouddynamical system to investigate the effect of aerosol on cloud optical properties, precipitation formation, and boundary layer dynamics in climatically important stratocumulus clouds (Feingold et al. 1999; Feingold and Kreidenweis 2002).

\subsection{Cloud Properties Research}

The broad goal of the Cloud Properties (CP) Working Group is to help develop and implement algorithms that characterize the physical state of the cloudy atmosphere. These algorithms combine measurements from various sensors to continuously estimate cloud macrophysical and microphysical properties with uncertainty estimates. A major difficulty with the development of such algorithms is that the cloud properties cover a variety of temporal and spatial scales, from interactions between individual cloud particles and radiation to scales comparable to those of the resolution of a GCM (several hundred kilometers). Long-term observations of the atmosphere provide information sufficient to affect improvement in our understanding of atmospheric physics, although translating this knowledge into model improvement may be difficult. Long-term continuous observations of clouds have contributed to our understanding of middle latitude cirrus, tropical cirrus, and Arctic clouds. They have also provided new insights into how clouds overlap in the vertical dimension, which is different from what is typically assumed in large-scale models. 
The most significant achievements by the $\mathrm{CP}$ are:

- developed techniques to detect clouds and classify cloud type automatically

- produced climatologies of the vertical location and frequency of cloud occurrence

- developed and implemented techniques to retrieve cloud properties such as mean particle size, liquid water path (LWP), and ice water path (IWP) from ground-based sensors

- created a growing database of in situ cloud measurements acquired simultaneously with groundbased observations

- developed a technique for direct computation of broadband atmospheric radiative heating rates completely constrained by data.

Cloud Detection and Classification: The development of an automated technique to identify cloud occurrence (active remotely sensed cloud layer, or ARSCL) is a major achievement of the ARM Program (Clothiaux et al. 2000). ARSCL primarily uses active sensors, but also blends in results of passive sensors to deduce cloud location in the overhead column as a function of height and time. ARSCL is a key dataset for many ARM Program research applications including cloud frequency, cloud overlap, 3-D geometry, and cloud property retrievals. More recently, ARM has created techniques to automatically classify cloud type (e.g., cirrus, altocumulus, stratus, etc.), as well as altitudes of multiple cloud layers, (Wang and Sassen 2002a, 2002b). One technique for identifying cloud type has been validated by surface observations of cloud type for continental mid-latitude clouds at the SGP site. Cloud type is closely related to the composition (i.e., liquid, ice, mixed-phase), location (height), and other characteristics of clouds (e.g., precipitating or non-precipitating). Using these algorithms, statistical databases of cloud type have been derived, enhancing our understanding of the climatic effects of clouds and allowing us to determine how cloud type and altitude vary as a function of meteorological and other parameters. Further, because retrieval algorithms for cloud microphysical quantities are typically specific for certain cloud types, it is important to have accurate techniques for identification of cloud type before applying microphysical retrieval algorithms.

Climatologies of Cloud Occurrence: A climatology of the vertical distribution of the locations of cloud layers at each of ARM's three very different geographic locations (mid-latitude continental, tropical and arctic) has been produced (Lazarus et al. 2000; Mace et al. 2001). Representing the first-ever assessment of the complete vertical structure of cloud layers, these climatologies have led to new assessments of actual cloud overlap and how that overlap should be treated in climate models (Mace and Benson-Troth 2002)

Cloud Property Retrievals: Researchers in the ARM Program have produced a broad variety of retrieval algorithms for cloud properties, such as condensed water path and mean particle size. Algorithm development has focused primarily on stratiform clouds containing either liquid or ice, but not both (e.g., Mace et al. 1998; Matrosov et al. 1998; Dong et al. 2000; Shupe et al. 2001; Wang and Sassen 2002a; Min et al. 2003). ARM data sets of retrieved cloud properties are a major and unique contribution to cloud and radiation science. For example, they are much more extensive temporally than aircraft in situ observations and provide a spatially integrated context that is often not available from aircraft. While less extensive than satellite products, they are considerably more accurate due to the use of active sensors, and provide a necessary validation resource. For some quantities, such as cloud ice water path, no other 
measured data set exists. Retrieval data sets have been used to develop understanding of cloud processes, compare with CRMs, and develop climate model parameterizations.

In Situ Data sets: Although ARM is primarily devoted to ground-based measurements, the need to validate cloud property retrievals has led to an extensive effort to acquire in situ microphysical measurements over ground-based sensors. Most of these data have been collected over the SGP site, but ARM has also supported joint efforts with NASA in other locations. The ARM Data Archive now contains one of the more extensive sets of cloud microphysical data and represents an important resource for the broader community.

Broadband Heating Rates: Retrieved cloud properties are currently being used by ARM investigators to study radiative heating in the columns over the ARM sites and the effect of clouds on these heating rates. This particular project has been labeled the broadband heating rate profile (BBHRP) product. The term "broadband" refers to the fact that the heating is being evaluated across the entire breadth of both the infrared and solar (visible) spectrums, rather than a specific portion of the spectrum. The heating rate is calculated using state-of-the-art radiation codes supplied with information from ARM observations about measured and deduced characteristics of cloud structure. Information that must be supplied to the radiation code includes overall cloud coverage, fractional cloud coverage at many levels within the column, the phase of the water in the clouds (water or ice), particle size, and particle habit in the case of ice clouds. None of these variables is easy to measure and most require measurements from multiple, high-technology instruments that are combined in unique ways to "deduce" the required information. Substantial progress is being made in developing techniques to acquire and integrate such information.

\subsection{Cloud Modeling and Parameterization}

One of the critical issues facing the ARM program in its formative stage was how to relate observations and data analysis on the one hand to model evaluation and development on the other. In collaboration with the GEWEX Cloud System Study (GCSS) project (Randall et al. 2003a), numerical weather centers, and climate modeling centers, ARM pioneered the use of single column models (SCMs), along with CRMs, to address this critical issue. SCMs are essentially the model physics codes (radiation, cloud, convection, and turbulence parameterizations) from GCMs. They represent the evolution of the vertical profile of temperature, water vapor, and clouds averaged over a single grid box of a GCM - an area comparable to that monitored by ARM at its SGP site. CRMs are limited area models that are typically run at high resolution to resolve convective and cloud processes more directly.

The most significant ARM achievements in the area of cloud modeling and parameterization are:

- developed a methodology for new parameterization development and, using that methodology, new GCM parameterizations

- led the development of data sets that permit CRMs and SCMs to simulate observed cases

- provided new insights into the problems of cumulus parameterizations in GCMs using a combination of ARM data analysis and comparisons to CRM simulations

- coordinated projects for CRM evaluation using ARM data.

Parameterization Development: ARM pioneered the methodology and systematic use of SCMs and CRMs for the assessment of GCM parameterizations. As a result of several ARM/GCSS model 
comparison projects, virtually all major modeling centers now have a single-column version of their parent GCM. This facilitates the community effort of evaluating and improving GCM parameterizations by focusing on their underlying physics rather than on the mean climatology simulated by the full GCM. These activities have stimulated the development of more physically based parameterizations. Examples include the development of physically based cloud overlap (Mace and Benson-Troth 2002), methods to efficiently treat inhomogeneous clouds in radiation calculations (Pincus et al. 2003), a simple scheme of fractional cloud condensation rate used in the NCAR GCM (Zhang et al. 2003), and new closures of cumulus convection that are currently being tested (Zhang 2002, Xie et al. 2004). In addition, ARM has supported the development of the Multi-scale Modeling Framework (MMF) (Randall et al. 2003b), which removes conventional cloud parameterizations from a GCM and substitutes a limited CRM in each grid box.

Data sets for Model Forcing: Due to their spatially limited domain, CRMs require information on the horizontal flow of mass and water vapor in and out of the domain to simulate observed cases. SCMs basically require the same input as CRMs to simulate observed cases (Figure 5). When forced by the same data, SCMs and CRMs can be compared to see how some of the processes (such as convection) parameterized in SCMs are resolved by the CRMs. While the development of forcing data sets for these models has a long history, ARM research has significantly advanced the science. In particular, ARM researchers developed a variational analysis procedure that converts raw ARM data into SGP-averaged profiles of soundings, vertical motion, and horizontal advection of temperature and moisture (Zhang and Lin 1997; Zhang et al. 2001).

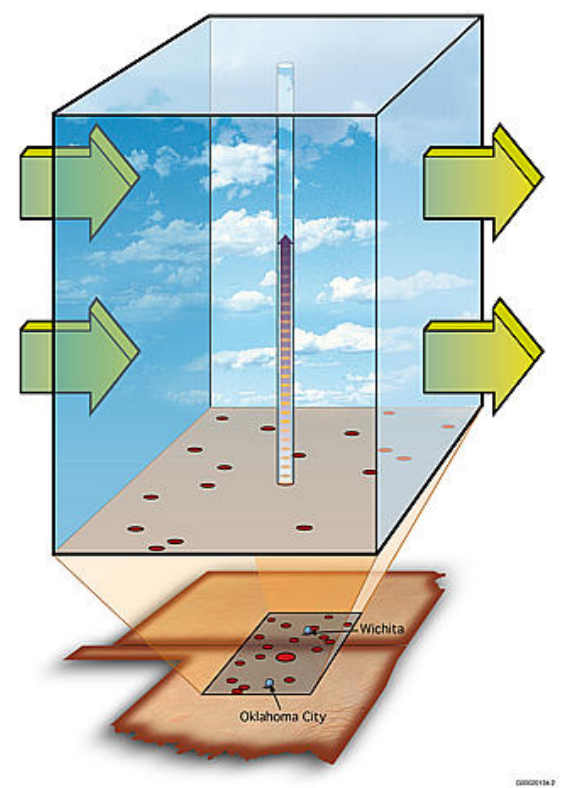

Figure 5. Representation of a Single-Column Model from the Southern Great Plains Site

The advances of variational analysis over previous analysis methods come primarily from two areas. First, the variational analysis approach adds conservation of column energy and water vapor as additional constraints; this enhancement was made possible by the availability of high-quality precipitation data over the SGP site. Second, the data themselves are adjusted through a variational procedure so that the column integrated budgets of mass, water, and energy are obeyed. These adjustments are consistent with instrument and sampling uncertainties. These two advances have produced estimates of large-scale state 
and forcing, which are superior to previous analyses procedures. In fact, the variational analysis procedure has been applied to other field experiments (e.g., TOGA-COARE), and has become the standard approach in the scientific community.

Producing an accurate data analysis requires a dense observing network; this is generally only possible during IOPs at the SGP site, and generally not possible at the other sites. While ARM has invested substantially at the SGP site in many SCM IOPs, it is desirable to produce forcing data sets for periods beyond IOPs. To fill this need, ARM researchers have developed a continuous forcing variational analysis product (Xie et al. 2003). This forcing set is produced without the enhanced radiosondes available during IOPs, but still obeys all the constraints of the normal variational analysis. In lieu of radiosonde data, analysis data from NWP centers' models are used as the first guess. The accuracy of this continuous forcing data is less than that of the variational analysis performed with data available during IOPs, but is still superior to traditional NWP analyses, particularly during the summer.

Improving Cumulus Parameterizations for Climate Models: Parameterization of cumulus convection is one of the most challenging problems in a GCM. To address this problem, ARM has led comparisons of SCMs and CRMs forced with the variational analysis from two summertime IOPs at the SGP (Ghan et al. 2000; Xie et al. 2002; Xu et al. 2002). These studies demonstrated that CRMs do a better job than SCMs in predicting the tendencies of temperature and moisture due to convection (Figure 6).

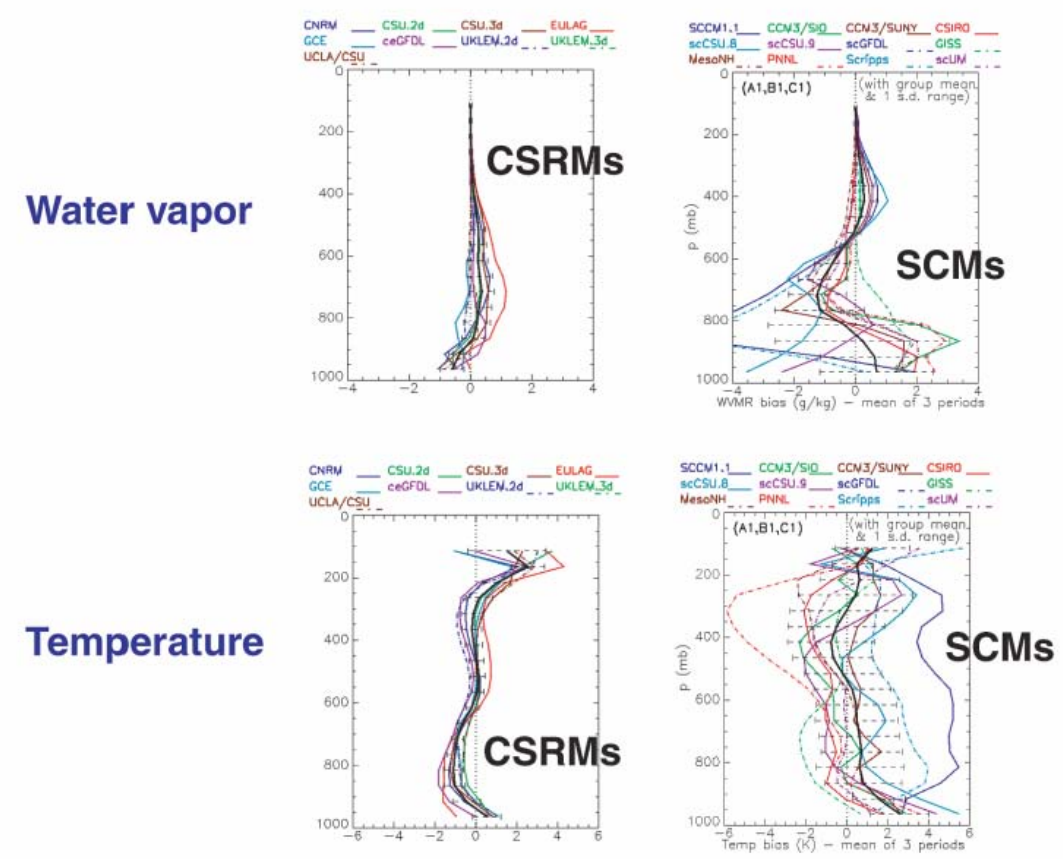

Figure 6. Comparison Showing Smaller Moisture and Temperature Errors in Cloud-Resolving Models Versus Single-Column Models (Randall et al. 2003)

This result suggests that CRMs can be used to assess problems with cumulus parameterizations in GCMs. In addition, data analysis by itself can point to problems and perhaps solutions for convective parameterizations. In simulations with the NCAR SCM, the cumulus parameterization produced precipitation nearly every day, whereas the observations indicated that precipitation was restricted to fewer events. The source of the problem lies in the closure assumption of the NCAR cumulus 
parameterization, which assumes that convection occurs whenever any convective instability occurs in the column. ARM observations clearly show this not to be the case, because the existence of instability in an atmospheric column is not sufficient for convection to occur. This finding has led ARM researchers to actively seek solutions to this problem, with potentially significant impact on NCAR GCM simulations of continental summer climate (Xie et al. 2004).

Testing Cloud Resolving Models: To use CRMs as a tool to improve cloud parameterizations in GCMs, it is critically important to evaluate these models. ARM data, however, point out lingering problems with CRM simulations. For example, data show that precipitation in CRM simulations tends to start later than observed (Xu et al. 2002). Also, while the tendencies of temperature and water vapor may be well simulated by CRMs, it is not obvious that the clouds themselves are well simulated. This may be because CRMs still must parameterize processes like microphysics, which determine the physical characteristics of the clouds. For example, using data from ARM retrievals of thin cirrus, research showed that the distribution of IWPs simulated by one particular CRM was skewed relative to observations (Luo et al. 2003).

\subsection{Interactions with Other Programs}

The ARM program is now recognized as an international leader in cloud and radiation sciences and has become a valued partner in a broad range of national and international programs. We provide here a short list of some of these partnerships.

- NASA Earth Science Enterprise. ARM has become one of the chief validation sites for earthorbiting satellites; there are many rich interactions between NASA and ARM-sponsored scientists and activities. These include studies of the column radiation budget and cloud properties measured simultaneously from above and below.

- GCIP. This ARM SGP measurements and data analysis were a critical element of this NOAA project. In return ARM received enhanced data sets and understanding of regional meteorology and hydrology.

- GCSS. ARM has supported scientists involved in these model comparison studies, as well as many data sets for model forcing and output evaluation. In return, the GCSS working groups have provided a focus for the study of problems of significant interest to ARM.

- ECMWF and the NCEP. ARM provides data for detailed weather model evaluation and testing, while the analyses provided by the operation centers are vital for understanding the context of ARM observations.

- The Australian Bureau of Meteorology (BOM). The combined activities of ARM and the BOM in Darwin have resulted in the best instrumented site in the global tropics. Shared operations and data make this a unique resource for the world's scientific community.

- Arctic System Science.

- Joint field activities. These comprise a very long list of joint activities with national and international partners to carry out detailed field studies of cloud and radiation properties.

We have long recognized in environmental sciences that such partnerships are critical because the problems we face are complex and resources are limited. It is clear to us that ARM has benefited scientifically from these collaborations and we expect more such collaborations to occur in the future. 


\subsection{Cloud and Radiation Physics - Building on past Success}

At this point, ARM has grown into a mature science program with well defined objectives and a well organized structure. As outlined in the preceding chapter, the ARM science team has been highly successful in solving a broad range of problems. Given this situation, the number one priority for the program as we look forward to the next five years is to maintain the course that has been set. The major themes of the program for the next five years are to:

- Maintain the data record at the remote sites at least through the next 5-year period.

- Improve significantly our understanding of and ability to parameterize the 3-D cloud-radiation problem at scales from the local atmospheric column to the GCM grid square.

- Develop new techniques to retrieve the properties of ice clouds and mixed-phase clouds and thereby improve our understanding of the life-cycle processes in these clouds and their interaction with atmospheric radiation.

- Develop a focused research effort on the indirect aerosol problem that spans observations, physical models, and climate model parameterizations.

- Implement and evaluate an operational methodology to calculate broadband heating rates in the atmospheric columns at the ARM sites.

- Develop and implement methodologies to use ARM data more effectively to confront atmospheric models, both at the CRM and the GCM scale.

Observational data sets envisaged in the initial program planning are now being acquired, but typically only extend five to eight years in length and have not reached the decadal length that was originally proposed. Most research to date has focused on the SGP site, but there is increasing use of the remote sites of the TWP and NSA. Thus, we begin this chapter with consideration of the individual sites.

As noted in the last chapter, ARM has, almost from its inception, been organized into working groups. While the research themes are cross-cutting, we still discuss them here under the basic working group organization. We do this for the sake of clarity, but realize that different parts of the themes appear in various sections below. One of the challenges of managing ARM science is to make sure that integration of the research themes occurs across the working group boundaries.

\subsection{Southern Great Plains}

The goals and activities for the SGP site during its next decade should build on its status as the original ARM site and, therefore, has the most comprehensive instrument suite and the longest and most numerous data streams. As such, the SGP site is well suited to support studies of regional climate and cloud variability on time scales ranging from seasonal to five-seven years. The value of the SGP data streams and the regional cloud-climate studies they permit will become more important as the science of climate modeling and prediction evolves. Substantial progress in that regard is expected during the next 10 years. 
It is vital to continue maintaining and improving the continuity, quality, and availability of data recorded at all SGP facilities, as well as to enhance their usability. This implies a continued strong emphasis on developing and maintaining routine data quality efforts, using the SGP as a testbed for new and improved instrumentation, and strengthening partnerships with other agencies and universities.

A concerted continuation of the established high-quality operations, maintenance, and calibration of existing instruments at the SGP improves the likelihood of attracting additional resources for instrument development. An example of this potential is the imminent introduction and deployment of a $95-\mathrm{GHz}$ cloud radar at the SGP, which will provide an exciting enhancement of its observing capabilities. The 95GHz radar will permit a more complete description of the variability of low clouds and their seasonal dependence because it is far less sensitive to biological contamination and because the higher temporal resolution provided by different scan strategies and greater processor speed will permit sampling down to nearly the range of turbulent eddies in the planetary boundary layer (PBL). This remote sensing of boundary layer energetics via the Doppler velocity field will shed light on the extent to which SGP stratus layers are decoupled from surface characteristics. The degree of boundary layer decoupling ultimately influences climatology through the effects on macroscale cloud properties such as cloud fraction and persistence.

Similarly, there is additional SGP instrumentation that will yield data that are important for ARM to fulfill its goals:

1. CCN Measurements: Quantifying the aerosol indirect effect over the SGP, from both remote sensing and in situ measurements, is an important goal of the ARM Program that aligns well with high priority research needs emerging from the U.S. CCSP. Although the prevailing air masses over the SGP tend to be continental in origin with high aerosol loads, the significant occurrence of cold season boundary layer cloud makes the SGP potentially a prime ARM location for exploring the indirect effect. Moreover, the presence of drizzle in some SGP PBL clouds implies the existence of periods of relatively low CCN concentration. The availability of routine $\mathrm{CCN}$ measurements would be of great help in addressing this issue, because the CCN number ultimately determines the cloud droplet concentration and hence, scattering crosssection. A better understanding of the behavior of the SGP boundary layer would enable the extension of surface point measurements of $\mathrm{CCN}$ into a vertical profile, which would be critical in determining cloud top droplet radii, thus quantifying this first indirect effect. The second indirect effect, involving the dependence of cloud lifetime on precipitation efficiency, may prove much more difficult to detect unambiguously over the SGP, given the short timescale of the continental mid-latitude large-scale dynamic forcing and the difficulty in quantifying precipitation efficiency. Despite this challenge, CCN measurements could be combined with measures of cloud system variability during conditions of relatively weak large-scale forcing to attempt to detect the second indirect effect.

2. Dual Polarization radar: The addition of dual-polarization capability on the current $35-\mathrm{GHz}$ MMCR would improve the retrieval of ice-phase particles relative to current cloud retrievals. Dual polarization radar can help discriminate ice-phase from liquid-phase particles and can be used to quantitatively estimate the amount of ice in a liquid/ice mixture. This capability can greatly improve mixed-phase microphysical retrievals and would greatly benefit the ARM goal of quantifying the cloud state over the SGP.

The enhanced observational focus on SGP warm season mesoscale convective systems (MCSs) that would be facilitated by the dual polarization capability described above would unite some of the aims of 
the ARM CP and CPM working groups. This emphasis would reflect the climatological significance of MCSs over the SGP and be representative of their wider role across the central MCSs affect the largescale distribution of atmospheric heat, moisture, and momentum, produce large regions of radiatively important cirrus, and provide a significant percentage of warm season rainfall that, in turn, strongly modulates the surface heat and moisture budgets. The ARM Cloud Parameterization and Modeling (CPM) Working Group desires a statistically significant sampling of SGP convective events. In situ particle measurements would provide vital data on detrained anvil (cirrus) particle size and habit occurrence, along with fundamental radiative characteristics like single scattering albedo and asymmetry parameters. These observations would be useful particularly for calibrating and testing cloud retrievals based on dual polarimetric radar observations, assuming the acquired observational capability advocated above.

Another scientific challenge for the SGP is to reduce measurement uncertainties related to the spatial distribution of surface albedo. These uncertainties affect the calculation of the aerosol direct effect and column heating. ARM samples a wide range of meso-climates and land-use categories over the SGP, which presents a challenging test for remote sensing of the surface albedo. Recent analysis of in situ ARM observations suggests multi-scale albedo variability in time (Hamm 2002). This implies that using seasonal or even monthly characterizations of albedo in calculations of the shortwave radiation budget might lead to significant error. The spatial and temporal variability should be further explored with surface, satellite, and airborne measurement platforms. An IOP is suggested to explore short-term albedo variability.

The shortwave radiation budget likely contains additional feedbacks resulting from the frequent occurrence of cold season low clouds over the SGP. Two key questions arise in this regard: (1) what are characteristic meteorological regimes associated with these clouds; and (2) are these canonical cloudtopped boundary layer clouds or do they exhibit more complicated dynamics? The variability of these low-level clouds in their meteorological context should be further explored. For example, the morphology and evolution of these clouds can be strongly modulated by the presence of precipitation. This prompts a further question -- how are these cloud differences reflected in key measures of cloud system variability? Investigating the characteristic variability will lead to a more complete description of cloud systems suitable for an ARM "value-added product" (VAP). Significant biases arise in GCMs and NWP model process rates when grid volume cloud parameter heterogeneity is neglected. Knowledge of cloud variability will lead to improved parameterizations of sub-grid physical processes in these models. Cloud system variability, expressed as a probability distribution function (PDF) of a fundamental model quantity like liquid water content, can be integrated with microphysical process rates to produce unbiased grid volume averaged rates. The SGP observational data also can address the closure problem - how to choose which PDF or family of PDFs based on resolved model variables. Cloud system PDFs and suitable closure assumptions constitute a treatment for sub-grid heterogeneity for use in GCMs and NWP models. 


\subsection{North Slope of Alaska}

Nowhere in the Northern Hemisphere are the interactions between clouds, the over- and underlying atmosphere, and the ocean surface more complex and, at the same time, less understood than they are at high latitudes. Yet, it is exactly at these high latitudes where climate models predict the first observable climate changes (Walsh and Crane 1992). Observations of high latitudes during the last decade show a complex suite of significant, interrelated, atmospheric, oceanic, and terrestrial changes taking place, disturbing the equilibrium upon which our limited understanding has been built. Sea-ice coverage is on the decrease, resulting in drastic impacts on surface radiative properties. Clouds in the Arctic may partially offset or even reverse these changes by modifying the surface energy budget; however, cloudiness itself is strongly dependent on the surface fluxes of heat and moisture, and thus on the sea-ice coverage. Moreover, much of the processes determining the microphysical characteristics and controlling the radiative properties of these clouds are unknown. In light of these scientific realities, the overarching goals driving ARM science at the NSA are:

- to increase our understanding of, and the interaction between, clouds, atmospheric radiation, and the surface

- to translate this knowledge into improved parameterizations of arctic cloud and radiation processes in GCMs

- to increase our understanding of the role of clouds in the arctic climate system.

Extensive spatial and temporal cloud coverage in the Arctic has a large impact on the radiative budget of the Arctic system (Curry et al. 1996; Harrington and Olsson, 2001) with clouds having a cooling effect in the summer (up to $-59 \mathrm{~W} \mathrm{~m}^{-2}$ ) and a warming effect (up to 20-30 $\mathrm{W} \mathrm{m}^{-2}$ ) in winter (Walsh and Chapman 1998). Because of this strong cloud dependence, surface radiative fluxes are quite sensitive to perturbations in cloud properties and amount. The dominant cloud-type is low-level stratiform clouds (Curry et al. 1996), whose properties are closely linked to the surface energy and moisture budget. Therefore, the first-order questions to be addressed by the ARM Program are

1. What are the basic properties (e.g., height of cloud base, fractional coverage) of polar clouds as measured from the surface at Barrow?

2. Can the processes determining these basic properties of polar clouds be determined; i.e., do the distributions of these basic properties depend predominantly on the larger scale atmospheric flow, or are they determined by the local environment?

3. What are the magnitude and variability of the surface radiation budget in time and space?

Although the importance of cloudiness to Arctic climate has been recognized (Curry et al. 1996; 2000), we still lack knowledge of both the internal physical processes of arctic clouds and physical reasons for the large cloud fractions over the Arctic. Therefore, additional questions about the details of these processes need to be raised:

1. What are the critical parameters controlling the microphysical composition of arctic clouds? Can these be observed on a regular basis?

2. What are the distributions of the radiative properties of arctic clouds? Can these be quantified from surface based remote sensing observations?

3. How are the microphysical properties of arctic clouds affected by anthropogenic aerosols? 
Answers to these questions will be found in analyses and modeling of the long-term data and of data collected in IOPs. The first extensive ARM IOP, the Mixed-Phase Arctic Cloud Experiment (M-PACE) will be held in October 2004. This experiment will focus on the properties and radiative impact of mixedphase clouds. Deployed resources include a second ground-based remote sensing facility, enhanced radiosondes at four locations, two aircraft, and Aerosondes.

Climate models cannot yet capture the first order cloud processes necessary for proper predictions of arctic climate components (Curry et al. 1996; Randall et al. 1998). The critical question of cloudiness over terrestrial and coastal arctic regions needs to be addressed (see Tao et al. 1996). Several feedback loops between surface properties and cloud processes have been hypothesized (e.g., Curry et al. 1995a, b) and implemented in climate models (Vorosmarty et al. 2001), but even the directions of these feedbacks are uncertain. Evaluation of improvements from such changes of a single parameterization for application to arctic processes is difficult due to the complex interactions and feedbacks between various processes (Randall et al. 1998). Questions to be answered are:

1. Do the relationships between physical components of the arctic system in the hypothesized feedback mechanisms exist, and can they be quantified?

2. What are physical relationships between the various arctic cloud regimes and large-scale forcing?

Climate change in the Arctic could cause major perturbations in the global environment. While clouds and radiation play a central role in many of the recognized instability points in Arctic climate, they are only two components. The Arctic is a complex environment, with first-order interactions occurring amongst many components (i.e., snow, vegetation, sea-ice, ocean, etc.). It is therefore of critical importance that ARM participates with the Arctic science community to address critical questions; some ARM scientists already work in these cross-disciplinary areas. Where appropriate, ARM management must seize every opportunity for collaboration with existing scientific programs. The Study of Environmental Arctic Change (SEARCH) (SSC 2001) is one example, and the Canadian government has several ongoing projects as well. It is incumbent that ARM should become a critical element of most Arctic research programs, contributing our observations and expertise while benefiting from that of other programs.

\subsection{Tropical Western Pacific}

It has long been recognized that the TWP warm pool area acts as the driver of a heat engine regime that significantly influences the global circulation of the earth-atmosphere system. The basic science issues relevant to ARM TWP activities were well stated in detail in the previous ARM Science Plan. In brief, the issues discussed in that document include fundamental questions such as:

1. What are the magnitude and variability of the surface radiation budget in time and space?

2. What are the basic properties (e.g., height of cloud base, cloud fractional coverage) of tropical clouds as measured from the surface?

3. How do the distributions of these basic properties vary temporally, spatially, and from the maritime continent area to the open ocean?

4. What is the impact of clouds on the surface radiation budget? 
With regard to atmospheric radiative heating in the TWP, important issues include:

1. What are the radiative flux convergence and column heating in the tropical atmosphere?

2. What is the average atmospheric radiative heating profile and how does it vary in time spatially across the TWP domain?

3. How does the atmospheric radiative heating profile vary in time, particularly on the diurnal time scale?

And with regard to the physical processes of radiative transfer:

1. What are the magnitude and spectral dependence of water vapor continuum absorption in tropical atmospheres?

2. What is the physical mechanism responsible for this absorption?

3. What is the impact of the extreme 3-D tropical cloudiness on atmospheric transmission of solar radiation?

Examination of data collected at the TWP sites has led to additional science issues related to ARM TWP interests, including:

1. What are the formation and maintenance mechanisms for tropical cirrus? Cirrus, especially high thin cirrus, are routinely observed at Nauru far removed from deep convection. Research by several groups suggests that these clouds are formed locally by dynamically induced lifting; however, the specific mechanisms are not well understood. This type of cirrus has distinctly different properties from anvil cirrus.

2. What is the lifetime of anvil cirrus? How do cirrus anvils feed back to impact convective development?

3. What mechanisms control the transition from shallow to deep convection?

4. What role does radiation play in tropical wave phenomena like the Madden-Julian Oscillation?

5. To what extent is convection in the TWP governed by dynamical forcing and to what extent is it governed by thermodynamic/radiative forcing?

With these scientific questions in mind, the size of the TWP domain makes it obvious that satellites and modeling efforts must be included in any "observational strategy." Detailed knowledge and understanding garnered at the ARM sites can be used to refine algorithms used by these tools representing the larger domain.

The role of ARM observations in this light, then, is two-fold. First, ARM should collect measurements intended to directly address the questions of climatology and variability outlined above. Second, ARM needs to provide surface sites that can collect detailed measurements and inferred cloud and atmospheric properties at specific locations to serve as truth points for satellite retrievals and model calculations of surface and atmospheric quantities. The Atmospheric Radiation and Cloud Station (ARCS) instrument and infrastructure package has been developed and deployed at three sites to fulfill these two basic roles. The ARCS design and TWP siting strategy processes included determining what quantities must be measured and how and where these measurements should be made. Recognition of logistical and financial constraints, including such factors as the extremely limited infrastructure support throughout much of the area of interest, potential political problems and instabilities in some areas, and the high cost of installing and maintaining instrumentation, were factored in the decision making. These issues are the principal reason there has not previously been the type of long-term measurement activity in the warm 
pool region that ARM has now successfully implemented. While these challenges have indeed been formidable, the ARCS design - coupled with the paradigm of using trained local observers for day-today operation - has produced long-term, scientific quality data of many atmospheric and cloud geophysical parameters. These data have in turn been applied to the quantification and analysis of many of the climate variables of interest to ARM, and related to some of the fundamental questions listed above. At present, many of the initial operational problems naturally inherent in such an ambitious endeavor have been successfully addressed. We are poised, for at least the next five years, to gather a continuous multiyear data set to address the relevant issues.

In addition to advances in our understanding as a result of the long-term record, there have also been some shorter term focused efforts. An IOP conducted near Nauru in mid-1999 included two research vessels: the NOAA RV Ron Brown, and the Japanese RV Mirai. The Nauru99 experiment produced a number of results, including refinement of our understanding of air/sea interface fluxes, area representativeness, and detection of an island effect on the ARM ARCS measurements. This last result led to another IOP, the Nauru Island Effect Study, intended to quantify the extent of the island effect on particular quantities, and thus account for them in the statistics generated from the measurements. The 18-month measurement phase of the Nauru Island Effects Study was concluded in mid-2003. Subsequent analysis of the data has produced a statistical quantification of the island influence on the ARCS measurements, and development of techniques to detect from the data - with a fair degree of certainty when these island effects are occurring.

Currently in the planning stages is an IOP to be conducted in the Darwin area during the 2006 monsoon season. This field campaign will include frequent launches of radiosondes from six sites, including Darwin, that are intended to help produce a data set suitable for SCM and CRM efforts. In addition, multiple aircraft will sample cloud and radiative properties from the variety of convective clouds that typify the Darwin monsoonal regime. Monsoonal convection is less violent (exhibits weaker vertical motion) than typical tropical continentally influenced convection, such as that sampled during the CRYSTAL/FACE and EMERALD experiments. It is expected that the convection sampled during the monsoon will better represent conditions in the tropical warm pool oceanic environment.

Finally, we believe it is time to conduct a review of ARM science goals and efforts with respect to the TWP. As pointed out before, the years of continuous TWP data currently residing in the ARM Archive represent an unprecedented resource for scientific research. These data have tremendous scientific value and are being used in a broad spectrum of research studies. However, given the current situation with regard to resources and the problems that have been encountered in operating sophisticated instrumentation in the harsh and remote tropical Pacific environment, questions do arise. For example:

- Is the current suite of ARCS instruments and measurements adequate and sufficiently accurate to accomplish ARM's initial scientific goals? In addition, there have been significant problems with data continuity for the more sophisticated ARCS instruments, particularly the millimeter wave cloud radar (MMCR) and micropulse lidar (MPL). How has this lack of continuity affected our ability to address some of our TWP questions?

- Has our understanding of tropical processes revealed any new areas that we should be including in our scientific goals, which perhaps need new, different, or better instrumentation? 
- How representative are the measurements from the three TWP sites, and of what regime(s)? We know the maritime continent is important. Are the Manus measurements adequately representing the maritime continental regime?

- Are we adequately addressing the Inter-Tropical Convergence Zone region? The large island region? The South Pacific Convergence Zone region?

The TWP Site Scientist office convened a workshop for the express purpose of seeking input and advice in a review of our TWP science strategy. The workshop was attended by respected researchers in various atmospheric science disciplines related to tropical research, including members of the modeling and satellite communities. Results of this workshop are being reviewed and will help define future directions for the TWP.

\subsection{Instrumentation}

During its early years, the ARM Program actively promoted research on a broad range of instrument science, from concept design to building prototypes to improvements in existing hardware and firmware. The result of this activity was the creation of a new generation of ground-based remote sensing instruments. The current instrument collection at the ARM sites was largely completed by 1996. Since then, instrument development within ARM has been relegated to modest improvements of existing instruments. To some extent, this has been a positive approach for ARM science. The instrument collection was relatively complete in terms of measurement capability and the lack of changes in the system provided continuity in terms of data type and quality. This situation has, however, had two unfortunate consequences: aging instruments leading to higher frequency of breakdowns and, to some extent, ARM has not kept completely abreast of observational technology.

The impact of aging instruments is most severely felt in the case of the active sensors, particularly the MMCR and the MPL. The MMCRs worked very well for several years, achieving better than $90 \%$ reliability at several locations. More recently, the systems have experienced breakdown due to a variety of causes. While the MPL at the SGP Central Facility has worked well, the reliability of MPLs at other sites, particularly in the tropics, has been poor. This is attributable to a number of design and operational flaws, which are being remedied. The related science issue is that periodic loss of data from critical instrument systems has a deleterious impact on research in many areas that are very important to the program. The ARM Program must make a concerted and continuous effort to upgrade existing systems and maintain them in operational status. Observing systems require upgrades not just in existing hardware, but in the use of new hardware and new processing systems. Rapid advances in computer technology coupled with, in many cases, decreasing prices, present the enviable opportunity to improve current systems, resulting in better data in terms of frequency, reliability, and new products given appropriate resources.

While there is virtue in continuing to provide a steady stream of data from well understood and stable instruments, fostering innovative research to some extent requires new measurements. In some cases, the instruments for these measurements exist but only in research mode; in other cases, the instruments do not exist or exist in concept only. Examples of identified research needs include

- improved processing capability on existing MWRs, including faster data acquisition, polarization, and Doppler spectra 
- addition of radars at other frequencies, both millimeter and centimeter, for dual wavelength retrievals

- lidar de-polarization measurements at all sites, but particularly the NSA

- routine observations by shortwave spectrometers at moderate resolution for spanning the spectrum, and at high resolution for specific bands such as the $\mathrm{O} 2 \mathrm{~A}$-band

- implementation of techniques to measure small LWPs, possibly either more microwave radiometer channels or enhanced longwave sensors

- implementation of techniques to measure IWP

- determination of consistent day/night cloud cover from sky imagers using some combination of longwave and shortwave sensors

- measurements of aerosol $\mathrm{CCN}$ on a routine basis

- determination and implementation of techniques to measure the near-instantaneous 3-D structure of clouds on the horizontal scale of $1-10 \mathrm{~km}$.

To remain at the cutting edge of ground-based remote sensing, ARM needs to regain its early initiative in instrument research and development. The best way of accomplishing this is through the re-creation of an instrument development fund that is used to target specific solutions and manage them to completion.

\subsection{Radiative Transfer Studies}

Major hurdles facing ARM in radiation studies lie within the general area of radiative transfer in cloudy atmospheres. Overall, clear-sky radiation problems have reached a point where any remaining discrepancies between observations and calculations, at least for midlatitude conditions, are small and can largely be relegated to a second priority. The cloud-radiation problems are most easily broken into two areas: (1) parameterization of cloud properties, and (2) 3-D radiative transfer.

Parameterization of Cloud Properties: Although considerable progress has been made in modeling the radiative properties of non-spherical ice crystals, there remains a poor understanding of the differences between model calculations and observations in terms of the asymmetry factor and scattering phase function, even after considering complicated particle shapes. Associated with this is the accurate determination of ice particle habit. Retrieved values of IWP - a critical quantity needed by cloud modelers - still contain large uncertainties. However, there are easily factors of 2 to 5 differences in IWP retrievals for different methods. Major sources of potential error include uncertainties in the actual concentrations of small ice crystals; the shape of ice particles, which determines the effective density, fall speed, extinction cross-section, etc.; and the mixture of different shapes or habits within a single volume. Ice particle habit also affects local radiative heating rates. This difficult problem requires coordinated research in several different areas. Clearly, ARM must continue to provide in situ observations of ice and mixed-phase cloud radiative and microphysical properties, collected simultaneously with remote-sensing observations, either from the ground or other aircraft. Additional research is needed to refine existing retrieval algorithms and develop new ones, especially for mixed-phase clouds. Theoretical and modeling studies, focusing particularly on the radiative effects of habit and size, are needed to interpret and suggest measurements. (Additional discussion of this topic is found in Section 3.7.)

3-D Radiative Transfer: During the past 10 years, ARM has funded many successful 3-D radiative modeling efforts aimed at improved understanding of subgrid radiative fluxes. The consistency among the various models is remarkable, but only so much can be learned from comparisons of detailed model 
calculations. It is now important for ARM investigations to use the knowledge gained to (1) clarify the climate problems for which 3-D radiative transport is important; (2) parameterize the detailed computations to GCM-required accuracy in terms of quantities that GCMs can calculate, and (3) validate the models for those conditions. ARM is well situated to contribute substantively to all three.

Customarily, the overlap of stratiform cloud layers has been discussed separately from 3-D radiative transfer, but the overlap problem is simply a subset of the general 3-D cloud problem. ARM measurements have enabled progress in developing advanced overlap algorithms and estimates of overlap probabilities. However, it is not yet clear that we have sufficient knowledge to adequately treat cloud overlap in GCM studies; this area requires further study.

The validation of parameterized codes could be of two forms for any given model, namely: (1) verification with time-domain 3-D radiative transfer models, and (2) validation with observations. The first will require the development of a database and a methodology to test GCM parameterizations for their ability to account for spatial complexity, irrespective of spectral complexity. The second will likely require fresh approaches to interpreting data measured by the vertically pointed instruments at the ARM sites, and to collecting 3-D data, the latter including methods such as scanning radar or lidar, balloon borne arrays of small inexpensive instruments (e.g. hot wire), or something akin to optical tomography. Developing and implementing these new techniques will require seed money for prototype development.

To account for subgrid variability in climate models, model-predicted variables for a particular grid cell may not be sufficient for describing the PDF in that cell. It may be necessary to have knowledge about surrounding spatial distribution of the model-predicted variables. To understand and quantify subgrid variability as related to scaling, it may be necessary to consider collecting data using a nested grid approach rather than the irregular spacing now employed at SGP. For this type of 3-D study, spatial coverage would be paramount over absolute accuracy. This approach would require the development of inexpensive autonomously operated systems capable of collecting basic meteorological and radiometric data.

Radiation Instrumentation Needs and Special Experiments: Various validation activities will continue using the already installed instrument suite as well as new instruments and modifications of existing devices. Overall, it is important that ARM maintains reference standard measurements, instrument suites and techniques, for broadband infrared and solar diffuse which are traceable to other emerging national and international references. An evaluation should be made of the achievable routine accuracy for broadband instruments in continuous operation at ARM sites relative to that achievable under the most controlled conditions.

One of the weaknesses listed in the measurements of atmospheric state section of the 2000 IRF report is the lack of routine cloud optical and microphysical properties. The CP has made great strides to address this in the last three years at the SGP site, and some of these products should be operational ARM data streams soon. Nonetheless, it is not clear that these are sufficient to use in the various validation studies, particularly at low LWP values. ARM investigators should consider the data already collected by ARM in both IOP and operational modes, identify specific questions related to the detection of low LWP values, and then identify which ones are not addressed by the current data sets. Problems that require additional or specialized data will likely be addressed subsequently through a series of IOPs, such as were carried out to understand water vapor measurements. Broken cloud model validation will require 
measurements of the optical depths of broken cloud fields. Barker and Marshak (2001) have reported progress on this problem by using a combination of ground radiance measurements above green vegetation at different wavelengths. Additional development of techniques of this type is required, along with routine albedo measurements in the vicinity of the ARM sites.

\subsection{Aerosol studies}

ARM measurements have concentrated primarily on measurements of aerosol optical properties (scattering, absorption, and extinction) because these parameters are required for assessing direct aerosol impacts on radiation. Nephelometer measurements of aerosol scattering have typically been performed at a few wavelengths (e.g., 450, 550, $700 \mathrm{~nm}$ ), while particle/soot absorption photometer measurements of aerosol absorption have usually been made at only one wavelength $(550 \mathrm{~nm})$. Consequently, estimating these aerosol optical properties at other wavelengths has required assumptions regarding the spectral dependence of aerosol scattering and absorption. ARM should pursue measurements of aerosol absorption at additional wavelengths (e.g., 450 and $700 \mathrm{~nm}$ ) as well as AOT measurements at longer wavelengths $(1600,2200 \mathrm{~nm})$ to reduce uncertainties associated with these assumptions and to improve the ability to model these parameters.

Furthermore, additional measurements of aerosol composition as a function of size, leading to a better understanding of aerosol refractive index, would permit a better understanding of the sources of aerosols and would help evaluate the representation of aerosols in aerosol physical models and chemical transport models. These measurements of aerosol properties are needed as a function of altitude. The routine series of in situ aerosol profile measurements carried out at the ARM SGP site is a unique resource and should be continued at least for another year or two, and possibly expanded. Comparisons to date have shown that the profile measurements of intrinsic aerosol properties are reasonably correlated to the surface measurements on average, but are not correlated on a daily basis (Andrews et al. 2004). Because the reasons for this are not entirely clear, further research is needed.

Recently, the DOE Atmospheric Science Program (ASP) has been reshaped to focus on aerosol radiative interactions. As this new focus develops, it is imperative that the ARM Program and the ASP find ways to work together effectively. ARM has insufficient resources and expertise to model and measure aerosol chemistry and its impacts on both direct and indirect effects. Joint efforts between ARM and ASP could significantly improve our understanding of the relationship between aerosol chemical and physical properties and optical effects. This improved understanding should help reconcile measurements of aerosol optical properties with computations of these parameters using measured microphysical aerosol properties.

It is widely known that aerosol direct effect at the TOA is dictated by surface albedo as well as by aerosol optical properties. However, there has been no systematic quantification of errors incurred by inadequate knowledge of surface albedo. Mapping surface albedo over the globe is a formidable task, given that signals of surface and aerosols are not easily separated. ARM measurements provide ideal "platforms" to evaluate this important factor. The occasional in situ surface and aircraft albedo measurements are very valuable to demonstrate the problem, but not sufficient to quantify it. IOPs using surface, airborne, and satellite measurements to characterize the spectral and angular dependence of surface albedo, as well as seasonal and spatial variations in surface albedo, should be pursued. 
Estimates of the magnitude of the indirect effect of anthropogenic aerosol are still highly uncertain (IPCC 2001). This is due both to limitations in our knowledge of fundamental aerosol nucleation effects and because the small scales pertinent to indirect effects are not resolved in GCMs. Furthermore, so many factors can and do affect cloud and precipitation efficiency that it is difficult to attribute and quantify aerosol indirect effects relative to other effects. Many of these other factors are associated with atmospheric dynamics on a variety of scales and these dynamical factors have no or very weak connection with aerosols. On such factor, for example, is large-scale cloud movement such as the movement of frontal systems. Changes in cloud and precipitation efficiency associated with variations in frontal strength have little to do with aerosols. Likewise, a region may have steady cloud cover caused by a continual supply of water vapor. Under this circumstance, the driving force for precipitation efficiency is dominated by water vapor convergence. Therefore, to provide a meaningful link between aerosol and changes in cloud and precipitation efficiency, these other major influential factors must be accounted for.

Additional measurements could be performed at the SGP and NSA sites to address the aerosol indirect effect. Measurements of the aerosol number size distribution in the CCN size range $(\sim 40-500 \mathrm{~nm}$ diameter) would provide a surrogate for $\mathrm{CCN}$ that can be used to help determine which changes in observed cloud properties can be attributed to changes in the aerosol. Measurements of CCN number concentration at one or more supersaturation values (such as those acquired during the May 2003 Aerosol IOP) are desirable. These measurements of aerosol number size distribution and CCN concentrations would be also highly desirable as part of the AMF. By deploying the AMF to acquire these measurements at a variety of sites with different aerosol regimes, the response of clouds to differences in the $\mathrm{CCN}$ could be evaluated by analyzing the variance. Efforts also should be made to accomplish closure between aerosol size resolved composition measurements and CCN spectra, and between CCN spectra and cloud droplet spectra. The former would advance efforts to distinguish natural from anthropogenic $\mathrm{CCN}$, while the latter should advance quantification of the indirect aerosol effect.

To reduce the uncertainties associated with the aerosol indirect effect, efforts to model and measure indirect effects need to be better integrated, and methodologies for scaling up results from small-scale models to large-scale models need to be developed. ARM should pursue experiments designed to address this complex problem. Ideally, this would involve conducting special IOPs to characterize water vapor, aerosols, and clouds accurately to separate clouds susceptible to aerosol influence from other clouds. If such an experiment cannot be carried by ARM alone, ARM should pursue this research via partnerships with other organizations. ARM involvement in such an experiment could involve deployment of the AMF, support for additional research aircraft and/or instruments on research aircraft, or funding for individual science investigations as part of such experiments. An example of such an experiment is the Houston Environmental Aerosol Thunderstorm (HEAT) Project

(http://www.met.tamu.edu/ciams/heat/index.html). The main objective of this mission is to study how air pollutants and the urban heat island effect impact convection and precipitation; studying the impacts of aerosols on clouds could be a natural extension of this mission. Little attention has been given to the effects of aerosol on ice cloud properties. This is a particularly difficult problem given the lack of knowledge about upper troposphere aerosol, the role of aerosol in modifying ice crystal properties, and the long distances (due to higher wind speeds) over which such effects occur. ARM needs to give serious consideration to mounting a concerted research effort aimed at this problem.

ARM aerosol measurements should be fed into large eddy simulation (LES) models and single-column versions of global aerosol models used to estimate indirect effects (Zhang et al. 2002; Menon et al. 2003), 
so that the treatment of the influence of aerosol on clouds in those models can be evaluated with independent ARM measurements. SCMs should be evaluated by comparison with measurements and with CRMs and LES models (Feingold et al. 1999; Feingold and Kreidenweis 2002). Providing continuous aerosol measurements required for such experiments presents a challenge to the program. Recent efforts by the ARM Aerosol Working Group to develop and test surface-based retrievals of hygroscopicity (Feingold and Morley 2003) and CCN concentration (Ghan and Collins 2003), and to develop methods that use surface aerosol properties to describe aerosol/cloud interactions (Penner et al. 2003) may lead to viable retrievals of the aerosol information needed to test treatments of the influence of aerosols on clouds on a long-term basis.

\subsection{Cloud Properties}

Meeting the overarching objective of the ARM program to improve GCM cloud parameterizations requires recognizing and resolving a number of immediate challenges. It is critical for ARM to produce a continuous, complete, and rigorous description of the atmospheric physical state in the vertical column above the ARM core instrument facilities. This description must include both radiometric properties such as optical depth, single-scattering albedo, and asymmetry factor, as well as estimates of the up- and downwelling broadband flux profiles, and bulk cloud properties such as condensed water contents and mean particle size. The ARM program has recognized this need for some time and has begun to implement essential VAP algorithms to produce these properties. Producing these algorithms, however, is a difficult challenge, particularly in the context of matching VAP outputs to GCM parameterization components.

For example, GCM cloud parameterizations are inherently statistical formulations taken to represent some ensemble effect of the cloud microphysical state over some region of space and averaged over some time period. ARM data consist of high-resolution time series of vertical profiles of certain observables at a single point. Thus, there is a mismatch of time and space scales between model and observable. Further, the observable quantities are radiative in nature and are related to the cloud properties of interest through complex and uncertain relationships. For example, radar reflectivity is mathematically related to the sixth moment of the hydrometeor size distribution. Because parameterizations are generally based on either the mass (third moment) or area (second moment) of the size distribution, algorithms must be constructed to retrieve the latter from the former. This often necessitates the use of multiple data streams. It cannot be emphasized too strongly that it is critical to have algorithms that are complete with realistic error estimates. In the past, ad hoc approaches to error assignment have been used that were neither believable nor defensible. For ARM algorithms and the associated VAP data sets to be useful to ARM investigators and the broader scientific community, these ad hoc error assignments must be abandoned and replaced with mathematically robust error evaluations. While ARM has made great progress in the area of algorithm formulation, there are areas where substantial research efforts are still required.

To accomplish our goal of obtaining long-term records of cloud microphysical and macrophysical properties at multiple locations, we have identified a number of foci for future ARM research. These include improved algorithms for retrieving cloud properties and the construction of long-term, easily accessible cloud properties databases for use by, in particular, the modeling community. We need to develop improved retrieval algorithms that provide bulk microphysical estimates for all cloud types, work in all circumstances, and are complete with uncertainty estimates. An increased focus must be placed, in particular, on improving retrievals of mixed-phase clouds and the development of extended databases of their statistical properties. The mixture of phases has a large effect on cloud radiative properties, and the 
parameterization of mixed-phase clouds has a large impact on GCM simulations. Uncertainties in the retrievals of mixed-phase clouds from both ground-based sensors and from satellite algorithms are much greater than those from single-phase clouds. In addition, there are relatively few in situ measurements of mixed-phase clouds to document the spatial distribution of ice crystals and supercooled water and to identify the conditions under which they co-exist. Also, there is uncertainty in the physical mechanisms by which mixed-phase clouds form (e.g., what role do ultragiant nuclei play, what is the impact of seeding of water clouds from above). The effect of any "clumpiness" in the water and ice phase of clouds on the radiative transfer inside clouds is also not well known. A combination of in situ microphysical, single-scattering radiative, bidirectional reflectance functions, and development of improved and robust remote sensing techniques for the microphysical properties of mixed-phase clouds should be a major focus area for the $\mathrm{CP}$ in the coming years to answer these questions. These clouds have been identified as being especially prevalent and important in the Arctic and are the principal target of the M-PACE to be held at the NSA in Fall 2004. However, mixed-phase clouds are also important atmospheric constituents in the mid-latitudes and tropics.

A larger and more varied database of in situ cloud microphysical and single-scattering properties (e.g., scattering phase function) must also be obtained during focused IOPs. The IOPs should target cloud types that are important climatologically and about which we have relatively little knowledge (e.g., mixed-phase clouds, Arctic clouds, tropical clouds associated with oceanic convection). Not only are these in situ observations needed to validate remote sensing algorithms, but they are also needed for the development of improved parameterizations of physically based algorithms describing cloud processes for GCMs, and for evaluating the performance of model simulations. Much is still unknown about cloud properties, especially the importance of ice crystals with maximum dimensions smaller than 100 micrometers, in the determination of cloud mass and radiative properties. Because some remote sensing algorithms use such observations in the development of their retrievals, enhanced knowledge of these properties is crucial. In situ observations can also help us determine how phases are mixed within clouds, and how quickly different cloud particles fall, both effects being important for the representation of clouds in GCMs. Given current discrepancies between model simulations and varying remote sensing algorithms, in situ observations will play a crucial role in improving our understanding of the effects of clouds and climate, and indeed much past progress has been made using in situ cloud measurements.

Evaluating the accuracy of microphysical retrievals is difficult. The usual approach is to compare results from different algorithms with each other and with in situ measurements collected by research aircraft. Consistency checks using other data and calculations are also frequently conducted. These evaluation strategies are necessary, but likely are not sufficiently rigorous to establish the uncertainty of retrieval results in actual situations. For example, prior work suggested that the Doppler Moments retrieval algorithm would have an uncertainty on the order $50 \%$ for ice water content and $20 \%$ for median particle size. However, these estimates are an overall convolution of many sources of error that arise from uncertainties in the observations, assumptions, and the theoretical and numerical approach taken to solving the inverse problem. It would be helpful to understand the influence each data element and each assumption has on the retrieval.

In general, it would be helpful to understand whether more complicated algorithms really offer much improvement over simpler approaches and under what conditions. Overall, improvements are needed for quantifying the retrieval error as cloud property retrieval algorithms are integrated into ARM's operational processing stream in the coming few years. 
When results of retrieval algorithms are available for all different cloud types (type being identified from algorithms already developed with ARM funding), they can then be used to develop a long-term database of cloud macrophysical and microphysical properties at a variety of locations around the globe. These properties serve as input to the BBHRP, which is designed to compute vertical profiles of radiative heating. The BBHRP must be substantially improved so that these profiles are made available continuously along with uncertainty estimates. This project is currently largely focused on the SGP site, but needs to be expanded to the other ARM sites, as well as the AMF.

\subsection{Cloud Modeling}

From the outset of the program, ARM has recognized that cloud modeling must be an integral component of the overall research program. Interaction between model and data comes largely in two areas. First, ARM provides data to initialize and constrain limited area models, both SCMs and CRMs. SCMs consist of the parameterized physics for a single model column extracted from global climate and weather forecasting models. CRMs are high-resolution codes that contain explicit cloud-scale dynamics and varying degrees of cloud physics and chemistry operating over a limited domain. Both types of models require boundary conditions at model top and sides to run simulations. Second, ARM provides data to evaluate model performance. Comparisons include column thermodynamic properties, cloud properties, and radiative fluxes.

\section{Input Forcing Data Sets}

Southern Great Plains: To date the CPM has analyzed, to differing extents, three SCM IOPs (summer 1995, summer 1997, March 2000). The first of these IOPs helped define the usefulness of constrained variational analysis and different SCM simulation approaches. The second resulted in real physical insights about SCM cumulus parameterization deficiencies in areas such as downdrafts and triggering. Analysis of the third case is ongoing with a focus on cloud cover and microphysics parameterizations. IOP forcing data sets have been processed for at least eight other IOPs (spring and fall 1997, spring 1998, winter, spring, and summer 1999, and early and late fall 2000); these data sets are available for 1999, 2000, and 2001 at http://science.arm.gov/wg/cpm/scm/variational_cont/ .

The CPM strategy for future IOP analysis is influenced by the advent of the continuous forcing product that utilizes the rapid update cycle (RUC) analysis with variational constraints. Initial comparisons of continuous forcing with directly-derived IOP forcing show good agreement in non-convective seasons. In convective seasons, continuous forcing appears superior to a pure NWP analysis product, but does not always capture the strength of the dynamical forcing of convective events. Thus, we anticipate that the continuous forcing product will prove quite useful for accumulating long-term statistics that can be directly compared to ARM data. Given the difficulty in capturing the dynamical forcing during convective seasons, it makes sense to assign highest priority to analyzing the other summer and early fall IOPs to begin to gather a climatologically significant ensemble of convective events. Likewise, if funding exists for future SCM IOPs at SGP, these should focus on convective seasons, with continuous forcing (extended over several years) providing the baseline for analysis of other seasons dominated by synoptic forcing. 
Another desired development for the variational analysis is the incorporation, where available, of satellite and Raman lidar-based upper tropospheric humidity. This is needed because, as shown by ARM research, radiosondes, the primary input to weather analyses such as RUC, consistently underestimate upper tropospheric humidity.

Other Sites: The Nauru99 input forcing data sets are currently being processed. In one sense these data sets are not optimal for studying deep convection because of the suppressed conditions during that IOP and the minimal sampling of dynamical forcing. However, numerous examples of mid-level cumulus congestus clouds, a bane of many GCMs, were observed at that time. Analysis of Nauru99 would provide an interesting test of the mass flux spectra produced by SCMs and their sensitivity to mid-level humidity. A more thorough test of cumulus parameterizations in tropical monsoon conditions will be provided by the TWP International Ice Experiment, which is planned for Darwin in early 2006. At the NSA, an IOP focused on mixed-phase processes (M-PACE) will be held in October 2004; if successful, it should provide a good test of SCM predictions of the occurrence of mixed-phase clouds, a key question in GCM cloud feedbacks at high latitudes. In addition, because Arctic locations appear to fluctuate between a surface-atmosphere radiative equilibrium configuration during cloudy periods and non-equilibrium conditions when skies are clear, it will provide an intriguing test of interactions between SCM cloud, radiation, and surface physics parameterizations.

A greater challenge is the acquisition of multiple SCM/CRM forcing data sets at the TWP and NSA, which is needed to obtain climatically significant statistics. The logistical difficulties and expense involved in conducting SCM IOPs at the TWP and NSA sites, combined with their importance to global climate, suggests that ARM should devote resources to evaluating the usefulness of NWP products as drivers for SCMs. The sparseness of radiosonde or wind profiler inputs to NWP analysis products in these regions makes this a challenging proposition. As a first step, it would be useful to compare time series of NWP dynamical forcing in TWP locations with time series of ARM or geostationary satellite data products to determine whether or not convective events bear a close relationship to analysispredicted large-scale upward vertical velocity maxima. An additional exploratory issue is the feasibility of constructing continuous forcing for the NSA and TWP sites. Clearly, using continuous forcing with constraints is superior to using NWP products only at the SGP, but it is not obvious whether sufficient inputs exist to conduct variational analysis routinely at the other sites. At best, it may be possible to evaluate SCMs only in statistical fashion at these sites if multiple IOPs cannot be funded and continuous forcing is not viable.

\section{Analysis Techniques}

ARM Data Simulators: Historically, modelers have been slow to utilize new remote sensing data products. Reasons for this include the uncertainties in retrieved products (which, as noted above, are not always well specified), mismatches in spatial and temporal scales between models and observations, and the small fraction of resources devoted to the comparison problem compared to the amount of resources available for either modeling or data collection. Usage of data sets increases dramatically when efforts are made to produce "model-friendly" data products and "data-friendly" algorithms for sampling models in a manner consistent with the way an instrument observes. This should be a focus of future ARM efforts. It will require active collaboration between dataset producers and model developers. 
On the data side, consideration must be given to the sampling characteristics of a particular instrument, the inherent sensitivity of the remote sensing technique and its implications for biases in the derived product, and effects of assumptions made in the retrieval. On the model side, consideration must be given to the type of model and type of comparison being conducted, as well as to assumptions in the model about sub-grid scale processes. For comparisons of MMCR or MPL time series to CRMs, viewing the model as a probabilistic forecast of the instantaneous cloud field viewed by the radar or lidar may be the most sensible approach. For comparisons of SCMs to long-term statistics, the existing International Climatology Program (ISCCP) simulator might serve as a basis for a simulator that samples sub-grid cloud columns to produce radar- or lidar-like distributions. Such a framework would also allow for simple tests of different approaches to predicting sub-grid PDFs of cloud parameters. ARM's considerable investment in the WSI, given its unique field of view and unpublished retrieval algorithm, is unlikely to bear fruit without a concerted effort to interpret what it sees from the modeler's viewpoint. Prototypes for comparing both CRMs and SCMs to ARM VAPs have been developed; consolidating the algorithms in software made accessible to all will need to occur.

At the moment, these activities are occurring in individual research projects with some limited coordination at the working group level. There have been serious discussions about the creation of an ARM simulator code. The idea here is to create a set of software routines that could be used in either CRMs or SCMs to simulate actual ARM measurements. This activity would, in our estimation, significantly enhance the use of ARM data by the general modeling community. It is, however, an expensive undertaking and probably beyond the capability of our current resources.

Merging Satellite and Ground Based Data: The original concept of the SGP site was that cloud and radiation properties would be measured over a domain approximately the size of one GCM grid box. The current implementation of this concept is a single Central Facility, which has a full complement of passive radiometers and active sensors, a set of Extended Facilities, which have basic radiometry and surface meteorology, and four Boundary Facilities, which have the same instruments as Extended Facilities augmented by some modest remote sensing capability. While this configuration allows us to map surface fluxes across the domain, it fails to capture the 3-D structure of clouds and gives an inadequate measure of atmospheric advection across the domain, particularly for the condensed phase. This lack of measurements of the 3-D structure of the atmosphere on the scale of a few hundred kilometers remains a serious impediment to the linkage of observations and parameterizations. While ARM may in the future add some instrumentation, such as a scanning 35-GHz radar that would address some part of this problem, it is unlikely that resources would be available to truly resolve it. The situation is even more difficult at the TWP and NSA sites, which lack extended and Boundary Facilities for obvious logistical reasons.

Satellite data have the potential to solve at least some of this problem. Beginning with the launch of Terra in 1999, followed by Aqua in 2002, NASA has produced a new generation of high-resolution cloud products that include cloud fractional coverage, cloud height, and cloud optical properties. These products will soon be enhanced by the launch of a cloud radar (CloudSat) and a lidar system (CALIPSO) designed to fly in formation with Aqua. ARM is a valued partner of the NASA Earth Enterprise. We think, however, that this collaboration could go much further. It is certainly possible to imagine merging ARM ground-based and NASA polar-orbiting satellite observations, along with geostationary satellite observations, into a single 3-D view of atmospheric properties on the scale of a GCM grid box. This is not, however, a simple project. It requires a considerable effort, somewhat akin to data assimilation on a 
fine scale. The ARM Program is funding some small projects in this area, but achieving major success requires a much more dedicated and extensive effort than is currently underway.

Cloud Regime Statistics: Initial comparisons of SCM and CRM output to ARM data emphasized the ability to reproduce observed time series in detail. This approach was found to have several limitations. Despite improvements from constrained variational analysis, errors remain in the forcing data set due to sparse sampling of the dynamical fields, and it is difficult to separate model errors from forcing errors. Some models can evolve to dramatically different states in a few days in response to small changes in the initial state. Inadequate simulation of a particular weather event may or may not reveal systematic model biases of climatic importance.

More recent SCM research has either examined limited temporal extent "subcases" highlighting specific events (e.g., convective storms) or simulated an entire IOP as a series of short-term "forecasts" after spinup from repeated initializations. Both approaches lead naturally to the investigation of ensembles of cloud "objects" or regimes. "Objects" indicate the repeated occurrence of a particular type of weather, as defined by surface rainfall rates, boundary layer structure, etc. Regimes are characteristic combinations of large-scale dynamical fields such as vertical velocity, wind direction, pressure, temperature, etc. that are diagnostic of fronts, cold air outbreaks, etc.

There are several advantages to these approaches: By examining statistics of many events, random errors in forcing only superimpose scatter on observed relationships. The problem of comparing point data to coarse resolution models can be addressed, in principle. Most importantly, we can identify systematic model biases and, perhaps, specific atmospheric conditions or phenomena that are associated with such biases. Given a long enough time series, such as might be produced from continuous forcing, the effect of systematic perturbations in the sign and strength of the forcing can be documented and models' cloud response to those perturbations compared with the observed cloud response. In this way parameterization improvement can be targeted at those aspects of the model that are most deficient and that might have the most impact on cloud feedbacks.

Initial Condition GCM analysis: During the past two years, ARM, along with the DOE Climate Change Prediction Program (CCPP), has supported efforts to develop a framework for initializing the NCAR Community Atmosphere Model to test its simulation of the 4D evolution of observed weather events. The standard approach to evaluate parameterizations in a GCM is to focus on how a given parameterization impacts the model's climate statistics and/or their perceived departures from the observed climate. This approach limits accurate identification of specific parameterization deficiencies because the GCM climate statistics often reflect compensating errors in the simulation of many different processes. As an alternative, CCPP-ARM Parameterization Testbed (CAPT) advocates comparison of short-range weather forecasts from a GCM against high-frequency ( $\sim 6$ hourly) NWP analyses. The challenge for CAPT is to make the connection from weather to climate and specifically to ARM data. The cloud regime framework described above might be used for this purpose.

Data sets used for diagnosing parameterization performance will be at both the global scale and local scale. On the global scale, CAPT will rely on high-quality NWP reanalyses. However, an NWP analysis is not sufficient to evaluate the GCM short-range forecast in all respects. Although the analysis is an optimal estimate of atmospheric state variables (given the available weather observations), it cannot furnish precise checks on physical forcings — such as radiation and its interaction with clouds, 
convective processes, and turbulent fluxes - because these depend strongly on the physical parameterizations of the assimilation forecast model. For independent evaluation of GCM physical parameterizations, high-frequency satellite data and field observations such as those provided by the ARM Program are indispensable - indeed, their practical value for identifying GCM parameterization problems has been demonstrated (e.g., Webb et al. 2001; Morcrette 2002). While global data sets allow general model deficiency tendencies to be identified, it is the availability of local, high-frequency ARM data sets that facilitates the detailed parameterization diagnosis required for improving the treatment of physical processes.

The CAPT is a developing and unique resource. To the best of our knowledge, it is the only GCM testbed operating in forecasting mode. Progress to date on the project has been rapid and results are encouraging. Making full use of the CAPT, however, will require the participation of scientists beyond the small group currently involved in the initial development and testing. While some proposals for the use of CAPT may be funded as part of the ARM Science Program, an active program devoted to the use of CAPT demands more resources than ARM currently has available. This is unfortunate because the CAPT activity has the potential to be a very important bridge between the ARM data analysis and physical modeling efforts already in place and the climate modeling community.

\section{Cloud-Resolving Models}

Research efforts in the ARM CPM working group and in GCSS suggest that for the purposes of improving cloud parameterizations in GCMs, CRM simulations are invaluable. These improvements come about through detailed, generally physically based, analyses of CRM simulation results.

Evaluation of Cloud Properties Against ARM Data: CRMs are a potentially powerful tool for understanding cloud behavior because they explicitly represent cloud-scale dynamics that directly determine cloud formation. However, CRMs must parameterize sub-grid turbulence, cloud microphysics, and radiation. Experience with simulating the Summer 1997 CPM IOP suggests that while CRMs produce better temperature and moisture fields than SCMs, significant disagreements remain among CRM predictions of cloud vertical structure and cloud water content. In the next year or two, ARM data products will begin to include column microphysical properties instead of just cloud boundaries. A systematic exploration of the dependence of CRM cloud properties on their parameterized elements, leading to optimization of those parameterizations, should be a top short-term priority. This is a necessary condition for the uses described below; the community needs to clearly establish the extent to which CRM cloud fields can provide guidance to SCM parameterization development, or whether this guidance should be restricted to CRM dynamical fields.

Given the ever-increasing sophistication of microphysics parameterizations in GCMs, the demonstrated influence of microphysical processes on cloud feedbacks, and the inherent uncertainty in the derivation of microphysical properties from surface remote sensing platforms, it would be useful for ARM to increase its emphasis on microphysical measurements, including in situ data, in the future. CRMs can be directly evaluated against such data by "flying" an equivalent track through the model, thus providing the most direct possible validation of CRM cloud properties.

Process Understanding and Condensing to GCM Parameterizations: CRMs are capable of simulating physical processes on cloud system scales. Their potential in helping us to formulate GCM 
parameterizations has not been fully exploited. ARM should encourage the exploration of new methods of using CRMs to address issues such as convection triggering conditions, closure assumptions, mechanisms and magnitudes of convective and mesoscale updrafts and downdrafts, convection-PBL interactions, the importance of 3-D radiative transfer, etc. ARM should also encourage research geared toward condensing CRM results to mechanistic models that are suitable for implementation as GCM parameterizations.

Creation of an ARM CRM Database: The GCSS strategy envisioned CRMs as tools for the development of GCM parameterizations. ARM has led the way in realizing this goal, but bringing the GCSS vision to fruition requires that CRMs and CRM fields be made available to a broad audience. As a step in this direction, it would be useful to create high temporal and spatial resolution samples of the dynamical, thermodynamic, cloud and radiation fields simulated in a control run of a CRM at each of the ARM sites in at least two seasons. This output should be stored in the ARM Archive and treated as standard data products available to all users.

The critical issue, however, is the analysis of the simulations themselves. To make the best use of operational simulations, the ARM Program must fund research projects specifically tied to the use of these data sets. A critical mass of ARM-funded projects in this area is likely to attract other non-ARM investigators in much the same way that the current SCM and CRM efforts do. These CRM analysis activities will also couple strongly with existing ARM data analysis activities in order to evaluate model performance and accuracy. An increased demand for observable cloud properties for model comparison purposes is likely to produce improvements in the observational data and VAPs.

We anticipate that the open availability of CRM simulation data sets to the ARM community will promote vigorous new research on a number of fronts. These include evaluation of the CRM itself, production of improved and new data products, physical process understanding based on the CRM output, and parameterization development and refinement. We expect that these activities would have a direct and demonstrable impact on the improvement of cloud and radiation treatment in climate models.

Looking further, we can imagine the creation of an operational ARM CRM that would be run continuously over the ARM sites for at least one year and, perhaps, for multiple years. Such data sets would provide a valuable resource for many of the approaches discussed above. This effort would demand resources beyond the current capability of the ARM infrastructure to produce and manage the simulation output and beyond the resources of the ARM science team to analyze and use it.

\section{GCM Cloud Feedback Study}

AMIP-style Simulations: The ultimate challenge for ARM is to use its point observations of climate parameters on short to interannual time scales to gain insight into global climate changes and feedbacks on centennial time scales. In the absence of a large volcanic eruption during ARM's lifetime, the ARM data sets will be too short to directly document any forced climate changes. What, if anything, can we learn from unforced climate changes on observable time scales that is relevant to cloud feedbacks? How can we use SCMs to inform their parent GCMs?

In one GCM, fluctuations of tropical cloud properties over the past two decades and their relationships to sea-surface temperature (SST) and vertical velocity anomalies have been shown to be a reasonable proxy 
of that model's response to a doubling of $\mathrm{CO}_{2}$. Thus, ARM modelers plan to conduct similar simulations for a cross-section of GCMs to diagnose similarities and differences among the model's interannual cloud and radiation responses to climate anomalies. The results will also serve as part of ARM's contribution to the international WCRP-WGCM Cloud Feedback Intercomparison, which will form the basis for discussion of cloud feedbacks in the IPCC Fourth Assessment Report.

Enhanced Statistics at ARM Sites: As part of this GCM intercomparison, enhanced diagnostics should be accumulated at model grid points corresponding to the ARM sites for years in which ARM data exist. This will enable us to explore in detail the factors that determine observed cloud property variability, and should give us insight on differences among the short-term feedbacks of different models.

For the ARM data to be an important contributor to this effort, two things need to occur. First, the ARM data simulator philosophy described earlier must be realized, so that straightforward comparisons of models to ARM data can be conducted. Second, the representativeness of the ARM sites must be documented to guide our interpretation of the data in a regional context. One way to accomplish this is to compare the ARM data to satellite data on much larger scales; some work of this kind is already underway in ARM, particularly at the TWP, where ARM has three sites each with its own peculiar characteristics. An objective approach to this question might involve multivariate spatio-temporal clustering algorithms applied to satellite data and reanalysis products to determine locations and seasons that share similar climatic regimes as defined by an agreed-upon subset of cloud-climate parameter values and variability.

$2 x \mathrm{CO}_{2}$ Simulations: Observed variability on interannual time scales is not necessarily a good proxy for forced climate change on centennial time scales. This is because the general circulation may respond differently to different types of climate perturbations, and because forced climate change represents an adjustment toward a new radiative-convective state of the atmospheric column with no direct analog in the current climate. Thus, we also plan to conduct equilibrium doubled $\mathrm{CO}_{2}$ simulations with as many GCMs as possible to determine the relevance of simulated cloud variability on observed time scales to cloud feedbacks associated with longer-term forced climate change. It is not computationally feasible for all GCMs to conduct such simulations, which require control and experiment runs that are each many decades in length. As an alternative, we plan to supply doubled $\mathrm{CO}_{2}$ equilibrium SST and sea ice fields from one or more GCMs as a prescribed lower boundary condition for models that cannot perform the full climate change simulation. Climate changes in TOA radiation balance for such models can serve as an indirect indicator of how their climate sensitivity differs from the parent model that supplied the anomalous SSTs. It would be of particular interest to subject the MMF to such an SST field to provide an early indicator of the type of cloud feedback it produces.

\subsection{Cloud Parameterization}

A primary goal of the ARM Program is to improve the representation of clouds and related processes in GCMs. The implied purpose of this improvement is to more accurately model the cloud feedbacks that GCMs simulate in response to climate change, thus reducing the uncertainty in climate change predictions. Different types of efforts are underway to improve simulations by GCMs of clouds and their feedbacks. Specific studies are underway to improve the "nuts and bolts" level of parameterizations. Parameterizations make many assumptions about sub-grid scale structure and properties that can be assessed with ARM observations or CRMs driven with ARM data. Alternatively, more holistic efforts 
use diagnostic studies to assess whether the ensemble of parameterizations in a GCM simulate the correct life cycles of clouds and their relationships with other parameters, such as temperature and vertical motion. These diagnostic studies are essential to evaluating whether GCM clouds look enough like real clouds.

\section{Improving the "Nuts and Bolts" Level of Parameterizations}

Cloud parameterizations make many assumptions about the structure of clouds at scales smaller than the grid-box size of GCMs $(\sim 200 \mathrm{~km})$. These assumptions are key to predicting grid-box mean properties, such as radiation, and they can readily be tested with ARM data. Two illustrative examples of GCMs assumptions being tested by ARM are given below.

The Example of Cloud Overlap: One such assumption relates to the vertical correlation structure of clouds. An aspect of this assumption is known as the "cloud overlap" assumption, which says given partial cloudiness at different vertical levels of a grid box, a certain fraction of the upper level cloud lies above the lower level cloud. Because the amount of solar radiation reflected back to space depends on the column integrated amount of cloud, overlap assumptions play a key role. Fortunately, with cloud radar and the ARSCL VAP, we can now quantify the degree to which clouds overlap. One parameterization supported by radar data is that the degree of overlap tends toward maximum for clouds separated by a small vertical distance but tends toward random for clouds separated by a large vertical distance. The vertical scale over which the correlation changes from maximum to random appears to be a few kilometers for wintertime (e.g., frontal) situations, but is larger for summertime (e.g., convective) situations. This information generated by ARM data can be used directly in the GCMs.

Cloud parameterizations today have begun to predict the amount of variability in cloud properties (such as LWP) within a grid box. This variability then can be used improve the grid-box mean radiation. Again, assumptions about cloud overlap play a role: Do the thicker parts of clouds at one level lie above the thicker parts of clouds at another vertical level? These assumptions about the overlap properties within clouds, as opposed to the existence overlap discussed above, can be tested with microphysical retrievals from the cloud radar.

Once GCMs can predict the amount of cloud variability within a grid box, one needs an efficient way to calculate the grid-box mean radiation. One novel way developed by ARM researchers is to generate a sample of cloud profiles and use a different sample member in the radiation calculation for each wavelength band. This method is much more computationally efficient than performing full radiation calculations for every sub-grid sample of clouds. Although this introduces random error, the method will produce unbiased estimates of the radiation. This is an improvement over the current situation in GCMs that always yields a biased estimate of grid-box mean radiation when the same cloud profile is passed to every wavelength band.

The Example of Mixed Phase Clouds: Climate model simulations of global warming have shown that one key area that impacts cloud feedbacks to climate is the phase (liquid or ice or mixed) of clouds in the temperature range in which both phases may occur (roughly between 0 and $-40^{\circ} \mathrm{C}$ ). As the climate warms, a greater fraction of the atmosphere will have temperatures that permit liquid to occur. In some 
models, this causes clouds to have a greater fraction of liquid that, because of the differing fall speeds of the particles, leads to more reflective clouds, ultimately providing a negative cloud feedback, which dampens the amount of polar amplification simulated.

Originally, cloud parameterizations would specify the fraction of liquid condensate versus ice as a single function of temperature. In today's parameterization, the ratio of liquid to ice is the end result of the microphysical processes as cloud liquid and ice are treated as separate prognostic variables with parameterized processes such as the Bergeron-Findeisan converting liquid to ice. Thus, the phase ratio is not fixed and depends on the age of the cloud, cloud thickness, and other meteorological processes.

Although a great challenge, ARM is developing methods to infer at least the occurrence of mixed-phase clouds from cloud radar. As the remote sensing algorithms improve, it will be useful to ask a variety of questions of the data and GCMs. Initially, it may only be possible to determine the existence of mixedphase clouds. From this limited information, it is worth asking in which situations do mixed-phase, pure ice, or pure super-cooled liquid clouds occur? If the algorithms improve to the point where quantitative retrievals of liquid water and ice can be carried out, then direct comparison with model liquid and ice water contents can proceed. Ultimately, one would like to compare cloud structure in observations and models. For example, in deep-layered clouds, such as those that occur at NSA, does the region of pure ice come close to the melting level?

Another related question is the magnitude of the vapor pressure in the mixed-phase temperature region. Studies have shown that conditions in which the clear-sky water vapor exceeds ice saturation may occur on a wide scale. The degree to which this occurs can be assessed by examining retrievals of water vapor from instruments with good remote sensing capabilities, such as the Raman lidar (Comstock et al. 2004).

The Aerosol Indirect Effect: Effects of aerosols on cloud droplet effective radii and cloud lifetime are considered to be among the most uncertain climate forcings. Satellite data generally cannot measure cloud properties and aerosols at the same place and time, while field experiments can, but only for short time durations. ARM remote sensing data are being used to examine effective radius variations as a function of below-cloud aerosol extinction for fixed LWP under a variety of turbulence conditions. The long time series possible at the SGP combined with simultaneous below-cloud and within-cloud information should make it possible to separate subtle aerosol effects on clouds from the more prevalent meteorological variability and thus provide climatologically significant constraints to guide the parameterization of cloud droplet number concentrations in coupled climate-chemistry models.

Other Parameterizations: Clouds in GCMs are not the sole function of cloud parameterizations. For example, the amount of condensate in anvil clouds depends, in part, on the amount of condensate that is detrained from the cumulus updrafts parameterized in convection schemes. Improvements in cloud schemes without improvements in other processes important for clouds, e.g., convection and turbulence parameterizations, would be futile. One ongoing effort focuses on improving the closure parameterization of convective parameterizations. ARM should fund research that is directed towards improvements in these parameterizations, particularly focusing on extracting information from either observations or CRMs or LES and using this information to improve parameterizations. If a sufficiently accurate ARM continuous cloud microphysics product can be developed, then the parameterization of convective detrainment itself might be constrained. 


\section{Diagnostic Studies}

As ARM improves the "nuts and bolts" of cloud and other parameterizations in GCMs, it is necessary to perform diagnostic studies that assess the degree to which the ensemble of parameterizations capture the rich structure of observed clouds.

To evaluate models, tools need to be developed to sample GCMs in the same way ARM instruments sample the real world. These tools (described elsewhere in this science plan) will be employed in studies such as the two described below. A common element of these studies is the importance of assessing the behavior of GCM clouds statistically; that is, for a given situation, do GCMs do the right things on average?

The Example of Tropical Cirrus: Clouds generally last for hours, not days, and in some situations it may be possible to observe a complete life cycle from a ground site. For example, cirrus from deep convection may start out as thick precipitating clouds, which gradually become thinner and less opaque with time. From remote sensing at the SGP and TWP, one may try to observe how the vertical extent and physical properties of cirrus change as a function of time following formation by deep convection. Such studies may require combining the remote sensing of ARM with the capabilities of geostationary satellite data to track where the clouds observed at fixed sites originated. Furthermore, NWP analyses may also provide wind information needed to perform back trajectories. Additionally, it is useful to try to distinguish the properties of cirrus (e.g., particle sizes, ice water contents) not formed from deep convection from those formed by deep convection.

The Example of Midlatitude Frontal Clouds: Clouds near midlatitude fronts (e.g., cold, warm, or occluded fronts) tend to obey well-known patterns. For example, in the warm frontal sector, cirrus tends to occur first; later, the cloud base descends, until eventually a deep nimbostratus occurs. After the cold front passes, one often observes shallow stratocumulus in the cold-advection portion of a cyclone. With all of the data from cloud radar plus microphysical retrievals, one could composite ARM observations according to synoptic setting to determine the typical clouds observed in each sector of the cyclone. Compositing will require developing long-term observations for many cases; this is facilitated by the creation of VAPs from ARM data.

One can imagine performing such studies for other types of clouds (i.e., the frequency of multi-layer low clouds in the Arctic at NSA). One challenge of this work is how to "observe" the performance of GCMs. One might be able to use SCMs when run with the continuous forcing data sets. However, a big problem with the forcing data sets is that a key unknown — horizontal advection of clouds — is not included in the forcing because we lack observations. Consequently, it will probably be most useful to sample the full GCM output classified according to similar synoptic or cloud occurrence.

Evaluation of Model Clouds on Different Time Scales: To have confidence in cloud feedbacks in GCMs, variations of simulated clouds on different time scales should be evaluated against observations. This should start from the full GCM by using satellite data. The ISCCP simulator developed by Klein and Webb can greatly facilitate this effort. Causes of model-data differences will then be evaluated at the ARM sites, through collection and compilation of detailed column physics data, diagnostics studies, and $\mathrm{SCM} / \mathrm{CRM}$ simulations. 


\subsection{Using the Multi-scale Modeling Framework}

Recently, a new computational approach to the cloud-climate problem has been proposed and implemented. In this new MMF model (formerly called "superparameterization") all the cloud-related parameterizations are removed from a GCM and replaced in each model grid with a 2-D (height and longitude) cloud system resolving model, or CRM (Khairoutdinov and Randall 2001; Randall et al. 2003). The CRM explicitly calculates cloud properties from physical equations at a scale consistent with cloud dynamics. From the ARM perspective, the MMF has several immediately obvious advantages. First, the scale of computed cloud properties matches the scale of observations. Second, computed properties are much more closely related to actual observables. Third, the MMF can test incremental improvements in knowledge of physics.

While the concept of an embedded CRM is scientifically appealing, only limited climate simulations with an MMF have been carried out to date due to a combination of the newness of the concept and computational limitations. The critical question then is whether this new approach to climate modeling provides a significant improvement in the simulation of current climate overall compared to existing climate models and, more particularly, whether it improves the treatment of cloud properties both regionally and globally. To understand the strengths and weaknesses of the MMF, model output needs to be tested thoroughly and rigorously. ARM data are ideally suited for this purpose because of their detailed depiction of clouds, high temporal and spatial resolution, and long time series.

One of the primary uses of the MMF from our perspective is as a bridge between ARM data and GCMs with conventional parameterizations. There are two obvious ways to do this. The first is to use the MMF as a tool to understand how to aggregate data from the ARM scale to the GCM scale. Because the MMF produces cloud-scale output across the GCM grid, it can simultaneously simulate an ARM site measurement and the average cloud properties produced by a conventional GCM. Thus, it can be used to help develop an ARM simulator. As discussed above, such a simulator would dramatically increase the use of ARM data for all climate models. The second approach is to use MMF cloud properties to evaluate conventional parameterizations. If it can be shown that it does a credible job of simulating certain cloud properties, the MMF can become a transfer standard from observations to the GCM scale. This is likely to be a particularly useful approach to sort out discrepancies among results from different GCM parameterizations.

The MMF can also be used to investigate hydrologic feedback processes on the large scale. Current climate literature is filled with proposed feedback mechanisms related to water vapor and cloud processes. Some of these are relatively well accepted, others much less so. In many cases, we lack the ability to test these feedbacks because GCMs either don't incorporate the process or incorporate it through a parameterization that implicitly assumes the feedback process works. Because it includes cloud-scale dynamics and coupling to the larger scale dynamics, the MMF can be used to test some of these feedback processes in a direct and understandable way. Still, the MMF is under development and much remains to be understood about its performance; the extent to which feedbacks can be tested in it is not yet clear. However, it certainly can be viewed as a promising tool for these activities. With regard to ARM, the GCM then becomes an integral component of the feedback research discussed above.

The MMF is an exciting new development in climate modeling. We see it as a possible bridge between ARM data (and other new data sources) and conventional GCMs. While ARM is currently supporting 
some limited effort in MMF research, it is very unlikely that the current ARM science funding can be stretched to accommodate much more effort in this arena.

\subsection{Priorities and Resources}

The preceding sections have laid out a broad and ambitious agenda for continuing current ARM research into the next five to 10 year period. The ARM Science Program is well positioned to make real progress in each of the areas discussed. The rate of progress, however, will be constrained by the availability of resources, which have remained essentially constant.

Over the past few years, science management has made a concerted effort to trim away research that is not focused directly on the primary ARM mission and has transitioned to a heavier investment in complex data analysis and modeling. At this point, because the program has necessarily grown increasingly interconnected, it is very difficult to pare away any more of the breadth of the research program without damaging the health and vitality of the whole program. The principal research themes identified in the introduction to this chapter are cross-cutting and require scientific expertise in a broad range of subdisciplines. Consequently, the likely strategy for the research program will be to continue research on most, if not all, of these critical priorities. We anticipate that this strategy will result in steady progress but at a deliberate rate that could be accelerated if more science funding were available. A corollary is that the number of scientists who are involved in the program and able to make extensive use of the rich resources of the ARM archive will remain constant at best, and may even diminish slightly.

The more problematic issue is that in the absence of new resources, it will be very difficult to implement some of the more bold and innovative research methodologies discussed above. Creation of an ARM simulator, implementation of substantive research efforts using the CAPT framework or an ARM CRM, or a more ambitious MMF research program simply cannot be supported within the existing program. Shifting resources to these new efforts by sacrificing some part of the existing program is not possible because it would destroy some part of the very foundation on which these new efforts are to be built. Consequently, efforts in these areas are most likely to remain small and exploratory, unless additional funding becomes available. 


\subsection{ARM Mobile Facility}

\subsection{Science Rationale}

From its very beginnings, the ARM observation strategy was designed to study atmospheric radiation and cloud processes rather than as a cloud monitoring network. As a result, the strategy consisted of two components: (1) a set of fixed sites in climatologically significant locales that would be operated for at least a decade to provide long-term data sets and (2) one or more mobile facilities that would be deployed for shorter times at varying locales. ARM has, of course, carried out the first strategy component. We now intend to carry out the second by building and deploying an AMF.

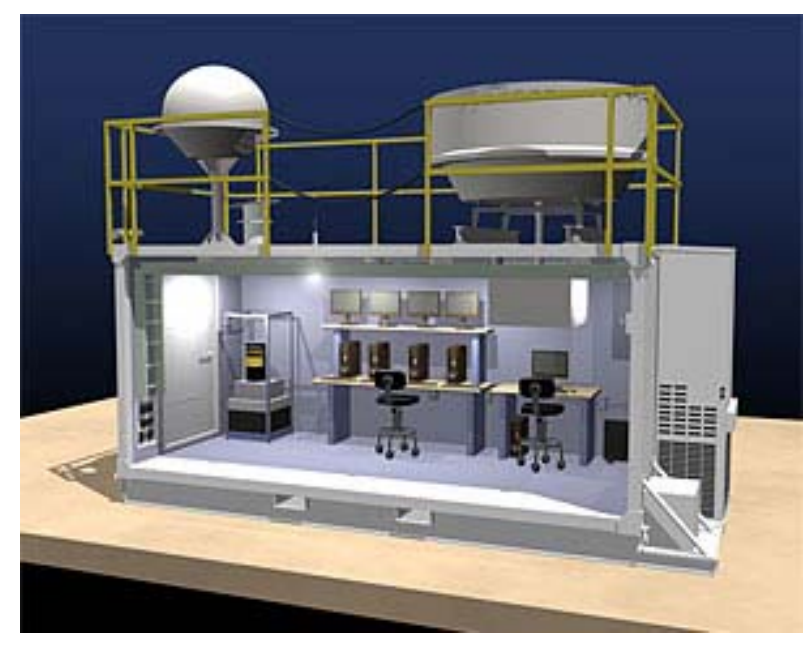

Figure 7. Artist's Rendering of the ARM Mobile Facility

The primary rationale for a mobile facility is the great diversity of climatic regimes on planet Earth. These regimes cannot be adequately sampled with a limited set of fixed sites. The AMF will allow us to obtain data from a greater number of locales, but for a substantially shorter time, because the intent is to deploy the AMF at any given locale for periods from a few months to a year. The choice of locale will be determined by several criteria. Most importantly, the locale must represent an important climatic regime not previously sampled by the program. If possible, the locale should offer the opportunity to collaborate with other science programs, either nationally or internationally. This might occur, for example, through large scheduled field programs using aircraft or as part of extended ground-based installations.

We held a special workshop and several discussion sessions to compile a list of potential science targets. Some of these are:

- marine stratus and stratocumulus

- North Atlantic and southern ocean storm tracks

- aerosol properties

- representative nature of current sites

- validation of satellite cloud products

- tropical forests 
- extended ice sheets

- monsoon climate

- anthropogenically polluted locations.

Further consideration of AMF use suggests that some locales might be used to address multiple targets. For example, in the case of aerosol properties, the optimal strategy will likely include aerosol measurements in most campaigns to sample aerosol properties at each locale, rather than target specific aerosol types with the AMF.

We expect that deployment of the AMF will benefit the ARM Program in a number of ways, some obvious and some less so. Clearly, the program will benefit from new data sets from other climatic regimes. These data sets can be used to expand our understanding of atmospheric phenomena, test models and algorithms developed in one locale against data from other locales, and increase the opportunity for validation of satellite retrievals. A prime example here is marine stratus and stratocumulus clouds. These clouds are extremely important regulators of climate but the current sites do not provide any relevant data. Deploying the AMF to a site where such clouds frequently occur would be highly desirable scientifically.

The AMF will expand the interaction of the ARM Program with other science programs, both national and international. This cross fertilization will enhance ARM as well as these other programs. The synergy achieved with NASA aircraft programs in the 2002 CRYSTAL campaign to study convection provides one example of this type of interaction. A prime consideration for future deployment is a locale that experiences interaction between variable aerosol concentrations and clouds. Such a deployment would strongly benefit ARM research into indirect aerosol affects and would very likely attract interactions with other programs, such as the DOE ASP, that are interested in the same problem and can bring aircraft resources to the AMF site.

Finally, we also expect that deployment of the AMF to different locales and acquisition of new data sets will lead to new science questions. Because of the complexity of the atmosphere, our science is often driven by discovery, i.e., the identification of previously undetected or unresolved phenomena, and then solution of their root causes. The AMF should enhance this process.

The AMF will deploy a suite of instruments that are quite similar to those deployed at the ARM remote sites, with some planned differences. Due to the anticipated short-time deployments of the AMF, data reliability is a much higher priority. Thus, detection of problems and instrument repair must occur more quickly than is usual at the current ARM sites. This in turn dictates that the AMF will be operated by staff that has a technical background and training beyond what is currently required at the ARM sites. It also dictates that there will need to be more active communication between ARM scientists interested in the AMF locale and the operational staff than occurs at the other sites. The AMF site scientist will play an important role in ensuring that this interaction occurs in a timely and efficient fashion. 


\subsection{AMF Design}

Portability and flexibility are the keywords in the AMF design, which will allow it to operate in any environment, from the cold of the Arctic to the heat of the tropics. The AMF will consist of a minimum of two lightweight shelters, a baseline suite of instruments, data communications, and data systems. It will also have the capability to be deployed in either an existing facility or in two ARCS instrument shelters developed for the TWP. The design includes the capacity (space, power, and processing) to add a significant number of additional instruments.

Instruments currently identified in the AMF design are very similar to those at the ARM remote sites. They include the standard set of surface broadband radiometers and meteorological instruments, a shadowband instrument, a longwave interferometer, a sky imager, and a microwave radiometer. Active sensing instruments include a micropulse lidar system and a 95-GHz cloud radar. (The current ARM radars operate at $35 \mathrm{GHz}$, but the $95-\mathrm{GHz}$ system was selected for its easier portability.) The AMF also includes a balloon-borne sounding system.

Shelter flexibility is a paramount consideration to deploy in various locales in a timely and cost-effective manner. Different locales will have differing constraints with respect to shelter requirements. The AMF design process currently considers several different options.

- Reusable shelters - The primary shelters are easily transported by land, sea, or air. These reusable shelters are approximately 12 feet long by 7 feet wide by 7 feet tall, with an empty weight of approximately $1500 \mathrm{lbs}$.

- Disposable shelters - Deployments are envisioned where the cost of deploying/recovering the shelter (transportation, customs, labor, etc.) is more expensive than the replacement cost of the shelter. In this case, a shelter that can be shipped to the deployment site on pallets, assembled, used, and then locally disposed of is a cost-effective solution. These types of shelters were used at the SHEBA ice camp and were made of foam laminated between plywood.

- Use of existing facilities - For many deployments, the use of existing facilities will be explored. If the larger instrument (cloud radar and lidar) are packaged so that they are stand-alone, the only required facility space will be for data system and instrument computers.

- ARCS shelters - The existing sea container shelters used at the ARM remote sites are relatively heavy and not amenable to portable operations. There may be some locales, however, which make the use of these shelters desirable. For example, if there is a plan to use a particular site several times, it might be desirable to pre-deploy these shelters to such a site and leave them for the duration.

\subsection{Priority and Resources}

The construction and deployment of the AMF is a very high priority for the ARM Program for the science reasons outlined above. This may seem contradictory in light of the comments at the end of Chapter 3 regarding the anticipated problems with funding continued operation of the existing ARM sites. The resolution of this issue is that no resources will be taken from the existing ARM fixed sites in order to construct or operate the AMF. As of 2003, the ARM sites have been designated the ARM Climate Research Facility (ACRF) and are now a DOE user facility. As a result, a modest increment of funding 
was inserted into the FY2004 budget to support ACRF. A substantial portion of this increment was designated for the AMF, and we expect it to continue in future years. The AMF is currently under construction and first deployment is expected in FY2005. Continued deployment is contingent on stable budgets because no funding will be diverted from existing site budgets to the AMF.

The AMF will strain existing ARM resources within the science team budget because we expect that AMF data sets will generate considerable scientific interest. The incremental funding for AMF operations, however, supplies no additional support for science investigations. Some of the data analysis and modeling associated with the AMF can be accommodated within existing science projects, but there is no doubt that AMF deployments will also spur new ideas and new proposals. These will necessarily compete with existing proposals for the same pool of funding and some will be successful. This will result in spreading the science funding across a broader research front.

The current budget for ACRF IOPs is fixed as well, and generally over-subscribed by the requests from various ARM scientists and staff. These IOPs serve a wide variety of purposes and have been very important in resolving important science and operation issues. There is no doubt that the AMF will attract IOP activity, including requests for aircraft time and additional instrumentation. Once again, these requests will compete with requests for IOP support at the existing sites. As is currently done, IOP priorities within ARM will be addressed on a case by case basis for all sites and decisions made on the basis of the needs of the entire ARM Program. 


\subsection{References}

Abdul-Razzak, H, and SJ Ghan, 2000: "A parameterization of aerosol activation, 2, Multiple aerosol types," J. Geophys. Res., 105: 6837.

Abdul-Razzak, H, and SJ Ghan, 2002: “A parameterization of aerosol activation 3. Sectional representation,” JGR Atmospheres, 107: 483.

Abdul-Razzak, H, SJ Ghan, and C Rivera-Carpio, 1998: “A Parameterization of Aerosol Activation. Part 1: Single Aerosol Type,” J. Geophys. Res., 103: 6123-6132.

Ackerman, T, and G Stokes, 2003: “The Atmospheric Radiation Measurement Program,” Physics Today, 56: $38-45$.

Ackerman, TP, DM Flynn, and RT Marchand, 2003: "Quantifying the magnitude of anomalous solar absorption,” J. Geophys. Res., 108: doi: 10.1029/2002JD002674.

Andrews, E, PJ Sheridan, and JA Ogren, 2001: "In-Situ Aerosol Profiles over the Southern Great Plains CART Site," In Proceedings of the Eleventh Atmospheric Radiation Measurement (ARM) Science Team Meeting, U.S. Department of Energy, Richland, WA.

Andrews, E, PJ Sheridan, JA Ogren, and R Ferrare, 2004: "In situ aerosol profiles over the Southern Great Plains cloud and radiation test bed site: 1. Aerosol optical properties," J. Geophys. Res., 109, D06208, doi:10.1029/2003JD004025

Barker, HW, and Z Li., 1997: "Interpreting Shortwave Albedo-transmittance Plots: True or Apparent Anomalous Absorption," Geophy. Res. Let., 24: 2023-2026.

Barker, HW, and A Marshak, 2001: "Inferring optical depth of broken clouds above green vegetation using surface solar radiometric measurements," J. Atmos. Sci., 58: 2989-3006.

Barker, HW, and 31 others, 2003: “Assessing 1D Atmospheric Solar Radiative Transfer Models: Interpretation and Handling of Unresolved Clouds," J. Climate, 16, 2676-2699.

Bush, BC, FP J Valero, AS Simpson, and L Bignone, 2000: "Characterization of Thermal Effects in Pyranometers: A Data Correction Algorithm for Improved Measurements of Surface Insolation,” J. Atmos. Oceanic Technol., 17: 165-175.

Byrne, RN, RC J Somerville, and B Subasilar, 1996: "Broken-Cloud Enhancement of Solar Radiation Absorption.” J. Atmos. Sci., 53: 878-886.

Cess, AD, MH Zhang, P Minnis, L Corsetti, EG Dutton, BW Forgan, DP Garber, WL Gates, JJ Hack, EF Harrison, X Jing, JT Kiehl, CN Long, JJ Morecrette, GL Potter, V Ramanathan, B Subasilar, CH Whitlock, DF Young, and Y Zhou, 1995: “Absorption of Solar Radiation by Clouds: Observations Versus Models.” Science, 267: 496-499. 
Cess, RD, MH Zhang, P Minnis, L Corsetti, EG Dutton, BW Forgan, DP Garber, WL Gates, JJ Hack, EF Harrison, X Jing, JT Kiehl, CN Long, J-J Morcrette, GL Potter, V Ramanathan, B Subasilar, CH Whitlock, DF Young, and Y Zhou, 1995: “Absorption of solar radiation by clouds: Observations versus models," Science, 267, 496-499.

Cess, RD, TT Qian, and MG Sun, 2000: "Consistency tests applied to the measurement of total, direct, and diffuse shortwave radiation at the surface," J. Geophys. Res., 105 (D20), 24,881-24,887.

Chuang, CC, and JE Penner, 1995: "Effects of Anthropogenic Sulfate on Cloud Drop Nucleation and Optical Properties," Tellus, 47B, 566-577.

Chuang, CC, JE Penner, KE Taylor, AS Grossman, and JJ Walton, 1997: “As assessment of the Radiative Effects of Anthropogenic Sulfate,” J. Geophys. Res., 102, 3761-3778.

Chuang, CC, JE Penner, KE Grant, JM Prospero, GH Rau, and K Kawamoto, 2002 : “Cloud Susceptibility and the First Aerosol Indirect Forcing: Sensitivity to Black Carbon and Aerosol Concentrations," J. Geophys. Res., 107, doi: 10.1029/2000JD000215.

Clothiaux, EE, TP Ackerman, GG Mace, KP Moran, RT Marchand, M Miller, and BE Martner, 2000: "Objective Determination of Cloud Heights and Radar Reflectivities Using a Combination of Active Remote Sensors at the ARM CART Sites," J. App. Met., 39: 645-665.

Comstock, JM, TP Ackerman, and DD Turner, 2004: "Evidence of high ice supersaturation in cirrus clouds using ARM Raman lidar measurements," Geo. Phys. Lett., 31, L11106, doi:10.1029/2004GL019705.

Curry, JA, JL Schramm, MC Serreze, and EE Ebert, 1995: "Water Vapor Feedback Over the Arctic Ocean.” J. Geophys. Res., 100, 14,223-14,229.

Curry, JA, J Schramm, and EE Ebert, 1995: “On the Sea Ice Albedo Climate Feedback Mechanism,” J. Climate, 8, 240-247.

Curry, JA, D Randall, and WB Rossow, 1996: "Overview of Arctic Cloud and Radiation Characteristics," J. Climate, 9, 1731-1764.

Davis, AB, and A Marshak, 2001: "Multiple Scattering in Clouds: Insights from Three-Dimensional Diffusion/P1 Theory," Nuclear Sci. Eng., 137.

DOE, 1996: Science Plan for the Atmospheric Radiation Measurement (ARM) Program. U. S. Department of Energy, Washington, D.C. DOE/ER-0670. 
Dong, X, P Minnis, TP Ackerman, EE Clothiaux, GG Mace, CN Long, and JC Liljegren, 2000: “A 25month database of stratus cloud properties generated from ground-based measurements at the Atmospheric Radiation Measurement Southern Great Plains Site,” J. Geophys. Res., 105, 4529-4538.

Dutton, EG, JJ Michalsky, T Stoffel, BW Forgan, J Hickey, DW Nelson, TL Alberta, and I Reda, 2001: "Measurement of broadband diffuse solar irradiance using current commercial instrumentation with a correction for thermal offset errors," J. Atmos. and Ocean. Tech., 18(3), 297-314.

Feingold, G, and SM Kreidenweis, 2002: “Cloud processing of aerosol as modeled by a large eddy simulation with coupled microphysics and aqueous chemistry," J. Geophys. Res., 107, D23, 4687, doi:10.1029/2002JD002054.

Feingold, G, and B Morley, 2003: “Aerosol hygroscopic properties as measured by lidar and comparison with in-situ measurements," J. Geophys. Res., 108, D11, 4327, doi:10.1029/2002JD002842

Feingold, G, WR Cotton, SM Kreidenweis, and J Thomas Davis, 1999: "Impact of Giant Cloud Condensation Nuclei on Drizzle Formation in Marine Stratocumulus: Implications for Cloud Radiative Properties," J. Atmos. Sci., 56: 4100-4117.

Feingold, G, WL Eberhard, DE Veron, and M Previdi, 2003: "First measurements of the Twomey indirect effect using ground-based remote sensors," Geophys. Res. Lett., 30(6), 1287, doi:10.1029/2002GL016633.

Feltz, W, W Smith, H Howell, R Knuteson, H Woolf, and H Revercomb, 2003: "Near-continuous profiling of temperature, moisture, and atmospheric stability using the atmospheric emitted radiance interferometer (AERI)," J. Applied Meteor., 42: 584-595.

Ferrare, RA, DD Turner, LA Heilman, O Dubovik, TP Tooman, and WF Feltz, 2001: "Raman lidar measurements of the aerosol extinction-to-backscatter ratio over the Southern Great Plains." JGR Atmos., 106: 20,333 .

Ghan, SJ, and DR Collin, 2003: “Testing a Cloud Condensation Nuclei Remote Sensing Method," In Thirteenth Atmospheric Radiation Measurement (ARM) Program Science Team Meeting, U.S. Department of Energy, Richland, WA.

Ghan, SJ, CC Chuang, and JE Penner, 1993: “A Parameterization of Cloud Droplet Nucleation. Part I: Single Aerosol Type,” Atmos. Res., 30, 197-221.

Ghan, SJ, CC Chuang, RC Easter, and JE Penner, 1995: “A Parameterization of Cloud Droplet Nucleation. Part II: Multiple Aerosol Types,” Atmos. Res., 36, 39-54.

Ghan, SJ, LR Leung, RC Easter, and H Abdul-Razzak, 1997: "Prediction of Cloud Droplet Number in a General Circluation Model,” J. Geophys. Res., 102, 21,777-21,794.

Ghan, SJ, G Guzman, and H Abdul-Razzak, 1998: "Competition Between Sea-Salt and Sulfate Particles as Cloud Condensation Nuclei," J. Atmos. Sci., 55, 3340-3347. 
Ghan, S, D Randall, K -M Xu, R Cederwall, D Cripe, J Hack, S Iacobellis, S Klein, S Krueger, U Lohmann, J Pedretti, A Robock, L Rotstayn, R Somerville, G Stenchikov, Y Sud, G Walker, S Xie, J Yio, and M Zhang, 2000: "A Comparison of Single Column Model Simulations of Summertime Midlatitude Continental Convection,” J. Geophys. Res., 105(D2), 2091-2124.

Ghan, S, R Easter, and J Hudson, 2001: "Evaluation of aerosol indirect radiative forcing in MIRAGE," $J$. Geophys. Res., 106, 5317.

Ghan, S, N Laulainen, R Easter, R Wagener, S Nemesure, E Chapman, Y Zhang, and R Leung, 2001: "Evaluation of aerosol direct radiative forcing in MIRAGE," J. Geophys. Res., 106, 5295.

Goldsmith, JE M, FH Blair, SE Bisson, and DD Turner, 1998: “Turn-Key Raman Lidar for Profiling Atmospheric Water Vapor, Clouds, and Aerosols," App. Opt., 37, 4979-4990.

Halthore, RN, S Nemesure, SE Schwartz, DG Imre, A Berk, EG Dutton, and MH Bergin, 1998: "Models overestimate diffuse clear-sky surface irradiance: A case for excess atmospheric absorption," Geophys. Res. Lett., 25, 3591.

Hamm, KG, 2002: "Comparison of Daily Broadband Surface Albedos Measured at Six Extended Facilities in the ARM Southern Great Plains Cloud and Radiation Testbed," In Proceedings of the Twelfth ARM Science Team Meeting, U.S. Department of Energy, Richland, WA.

Han, D, and RG Ellingson, 2000: "An experimental technique for testing the validity of cumulus cloud parameterizations for longwave radiation calculations," J. Appl. Meteor., 39, 1147-1159.

Harrington, JY and PQ Olsson, 2001: "A method for the parameterization of cloud optical properties in bulk and bin microphysical models. Implications for arctic cloudy boundary layers." Atmos. Res., 57, 5180

Harshvardhan, DW, R Green, SE Schwartz and CM Benkovitz, 2001: “An in-vestigation of the effect of sulfate on cloud microphysics using a chemistry/transport model. Preprints, A Millennium Symposium on Atmospheric Chemistry," Albuquerque, NM, Am. Met. Soc., 152-159.

Hogan RJ and AJ Illingworth, 2000: "Deriving cloud overlap statistics from radar observations," Quart. J. of the Roy. Meteor. Soc., 126, 1-7.

Hogan, RJ, C Jakob and AJ. Illingworth, 2001: "Comparison of ECMWF winter-season cloud fraction with radar derived values," J. Appl. Meteorol., 40(3), 513-525.

Jakob, C, and SA Klein, 1999: "The role of vertically varying cloud fraction in the parametrization of microphysical processes in the ECMWF model," Quart. J. of the Roy. Meteor. Soc., 125(555), 941-965.

Jakob, C, and S Klein, 2000: “A parameterization of the effects of cloud and precipitation overlap for use in general-circulation models." Quart. J. Roy. Meteor. Soc., 126, 2525. 
Kato, S, TP Ackerman, EE Clothiaux, JH Mather, GG Mace, ML Wesely, F Murcray, and J Michalsky, 1997: "Uncertainties in modeled and measured clear-sky surface shortwave irradiances," J. Geophys. Res., 102, 25881.

Khairoutdinov, MF, and DA Randall, 2001: "A cloud resolving model as a cloud parameterization in the NCAR Community Climate System Model: Preliminary Results,” Geophys. Res. Lett., 28, 3617-3620

Kim, B-G, S Schwartz, M Miller, and Q Min, 2003: "Effective Radius of Cloud Droplets by Groundbased Remote Sensing: Relationship to Aerosol,” J. Geophys. Res., 108, 4740.

Lazarus, SM, SK Krueger, and GG Mace, 2000: "A Cloud Climatology of the Southern Great Plains ARM CART," J. of Clim., 13, 1762-1775.

Leese, J, S Williams, R Jenne, and A Ritchie, 2003: "Data collection and management for Global Energy and Water Cycle Experiment (GEWEX) Continental-Scale International Project(GCIP)," J. Geophys. Res., 108, 8621.

Li, Z, and A Trishchenko, 2001: "Quantifying the uncertainties in determining SW cloud radiative forcing and cloud absorption due to variability in atmospheric background condition," J. Atmos. Sci., 58: 376-389.

Li, Z., 2004: "On the solar radiation budget and cloud absorption anomaly debate," In Observation, Theory, and Modeling of the Atmospheric Variability, World Scientific Pub. Co., 437-456.

Lohmann, U, J Feichter, CC Chuang and JE Penner, 1999: "Predicting the number of cloud droplets in the ECHAM GCM,” J. Geophys. Res., 104, 9169-9198 and 24,557-24,563 (Erratum).

Lohmann, U, J Feichter, JE Penner, and R Leaitch, 2000: "Indirect effect of sulfate and carbonaceous aerosols: A mechanistic treatment," J. Geophys. Res., 105, 12,193-12,206.

Luo, Y, SK Krueger, GG Mace, and K-M Xu, 2003: “Cirrus Cloud Properties from a Cloud-Resolving Model Simulation Compared to Cloud Radar Observations," J. of the Atmos. Sci., 60, 510-525.

Mace, GG, and S Benson-Troth, 2002: "Cloud-Layer Overlap Characteristics Derived from Long-Term Cloud Radar Data,” J. of Clim., 15, 2505-2515.

Mace, GG, TP Ackerman, P Minnis, and DF Young, 1998: "Cirrus Layer Microphysical Properties Derived from Surface-Based Millimeter Radar and Infrared Interferometer Data.," J. Geophys. Res., 103, $23,207-23,216$.

Mace, GG, EE Clothiaux, and TP Ackerman, 2001: "The composite characteristics of cirrus clouds: Bulk properties revealed by 1 year of cloud radar data," J. Climate, 14, 2185-2203.

Mace, GG, AJ Heymsfield, and MR Poellot, 2002: “On retrieving the microphysical propertieis of cirrus clouds using moments of the millimeter-wavelength doppler spectrum." J. Geophys. Res., 107: doi:10.1029/2001JD001308. 
Marshak, A, A Davis, W Wiscombe, and R Cahalan, 1997: "Inhomogeneity Effects on Cloud Shortwave Absorption: Two-aircraft Simulations,” J. Geophys. Res., 102, 16619-16637.

Marshak, A, WJ Wiscombe, AB Davis, L Oreopoulos, and RF Cahalan, 1999: "On the Removal of the Effect of Horizontal Fluxes in Two-Aircraft Measurements of Cloud Absorption," Quart. J. Roy. Meteor. Soc., 125, 2153-2170.

Matrosov, SY, AJ Heymsfield, RA Kropfli, BE Martner, RF Reinking, JB Snider, P Piironen, and EW Eloranta, 1998: "Comparisons of Ice Cloud Parameters Obtained by Remote and Direct Methods," J. Atmos. Oceanic Technolo., 15, 184-196.

Menon, S, J-L Brenguier, O Boucher, P Davison, AD Del Genio, J Feichter, S Ghan, S Guibert, X Liu, U Lohmann, H Pawloska, JE Penner, J Quaas, DL Roberts, L Schüller, and J Snider, 2003: "Evaluating aerosol/cloud/radiation process parameterizations with single-column models and Second Aerosol Characterization Experiment (ACE-2) cloudy column observations," J. Geophys. Res., 108, 4762 , doi:10.1029/2003JD003902.

Michalsky, J, E Dutton, D Nelson, M Rubes, T Stoffel, M Wesley, M Splitt, and J DeLuisi, 1999: "Optimal Measurement of Surface Shortwave Irradiance Using Current Instrumentation," J. of Atmos. and Ocean. Tech., 16, 55-69.

Michalsky, J, P Kiedron, J Berndt, T Stoffel, D Myers, I Reda, J Treadwell, A Andreas, S Asano, A Uchiyama, A Yamazaki, M Haeffelin, T Tooman, R McCoy, A Bucholtz, B Bush, S Pope, A Leitner, and FP J Valero, 2002: "Broadband shortwave calibration results from the Atmospheric Radiation Measurement Enhanced Shortwave Experiment II,” J. Geophy. Res., 107, 10.1029/2001JD001231.

Michalsky, JJ, R Dolce, EG Dutton, M Haeffelin, W Jeffries, T Stoffel, J Hickey, A Los, D Mathias, LJB McArthur, D Nelson, R Philipona, I Reda, K Rutledge, G Zerlaut, B Forgan, P Kiedron, C Long, C Gueymard, 2004: "Towards the development of a diffuse horizontal shortwave irradiance working standard," J. of Atmos. and Ocean. Tech., 16, 55-69.

Min, Q-L, M Duan, and R Marchand, 2003: "Validation of surface retrieved cloud optical properties with in situ measurements at the Atmospheric Radiation Measurement Program (ARM) South Great Plains site," J. Geophys. Res., 108, 4547.

Mlawer, EJ, SA Clough, PD Brown, and DC Tobin, 1999: "Recent Developments in the Water Vapor Continuum," In Proceedings of the Ninth Annual ARM Science Team Meeting, U.S. Department of Energy, Richland, WA.

Moran, KP, BE Martner, MJ Post, RA Kropfli, DC Welsh, and KB Widener, 1998: “An Unattended Cloud-Profiling Radar for Use in Climate Research,” Bull. Amer. Meteo. Soc., 79, 443-455.

Morcrette, J-J, 2002: "Assessment of the ECMWF model cloudiness and surface radiation fields at the ARM SGP site," Mon. Wea. Rev., 130, 257-277. 
Morcrette, J-J, and C Jakob, 2000: "The Response of the ECMWF Model to Changes in the Cloud Overlap Assumption," Mon. Wea. Rev., 128, 1707-1732.

O'Hirok, W and C Gauthier, 1998: "A three dimensional model to investigate the solar radiation within a cloudy atmosphere, Part II: Spectral effects,” J. Atmos. Sci., 55, 3065-3076.

Ovtchinnikov, M, and SJ Ghan, 2004: "Parallel simulations of aerosol influence on clouds using a cloudresolving model and a single column model," J. Geophys. Res., in press.

Penner, JE, D Hegg, and R Leaitch, 2001: "Unraveling the Role of Aerosols in Climate Change." Env. Sci. and Tech., 35, 332A-340A.

Penner JE, SY Zhang, and CC Chuang, 2003: “Soot and smoke aerosol may not warm climate,” J. Geophys. Res., 108(D21), 4657, doi:10.1029/2003JD003409.

Penner, JE, X Dong, Y Chen, 2004: “Observational evidence for a change in radiative forcing due to the indirect aerosol effect," Nature, 427, 231-234.

Philipona, R, 2002: “Underestimation of solar global and diffuse radiation measured at Earth's surface," J. Geophys. Res., 107(D22), 4654.

Pilewskie, P, and FP J Valero, 1995: "Direct Observations of Excess Solar Absorption by Clouds," Science, 267, 1626-1629.

Pincus, R, HW Barker, and J-J Morcrette, 2003: “A fast, flexible, approximate technique for computing radiative transfer in inhomogeneous cloud fields," J. Geophys. Res., 108, 4376.

Ramanathan, V, B Subasilar, GJ Zhang, W Conant, RD Cess, JT Kiehl, H Grassl, and L Shi, 1995:

"Warm Pool Heat Budget and Shortwave Cloud Forcing: A Missing Physics?" Science, 267, 499-503.

Randall, D, R Cederwall, S Ghan, T Del Genio, and S Krueger, 1998: “ARM Single Column Modeling...the Next Five Years," ARM 99-02, U.S. Department of Energy.

Randall, D, S Krueger, C Bretherton, J Curry, Duynkerke, M Moncireff, B Ryan, D Starr, M Miller, W Rossow, G Tselioudis, and B Wielicki, 2003a: "Confronting models with data: The GEWEX Cloud Systems Study,” Bull. Amer. Meteor. Soc., 84, 455-469, doi:10.1175/BAMS-84-4-455.

Randall, DA, M Khairoutdinov, A Arakawa, and W Grabowski, 2003b: "Breaking the cloudparameterization deadlock," Bull. Amer. Meteor. Soc., 84, 1547-1564

Rapp, AD, DR Doelling, MM Khaiyer, P Minnis, WL Smith, FP J Valero, and S Asano, 2001: "Comparison of Shortwave Cloud Radiative Forcing Derived from ARM SGP Surface and GOES-8 Satellite Measurements During ARESE I and ARESE II," In Proceedings of the Eleventh Atmospheric Radiation Measurement (ARM) Science Team Meeting, U.S. Department of Energy. 
Revercomb, HE, DD Turner, DC Tobin, RO Knuteson, WF Feltz, J Barnard, J Bösenberg, S Clough, D Cook, R Ferrare, J Goldsmith, S Gutman, R Halthore, B Lesht, J Liljegren, H Linné, J Michalsky, V Morris, W Porch, S Richardson, B Schmid, M Splitt, T Van Hove, E Westwater, and D Whiteman, 2003: "The ARM Program's Water Vapor Intensive Observation Periods: Overview, Initial Accomplishments, and Future Challenges," Bull. Amer. Meteor. Soc., 84, 217-236.

Schmid, B, J Michalsky, R Halthore, M Beauharnois, L Harrison, J Livingston, P Russell, B Holben, A Smirnov, and T Eck, 1999: "Comparison of Aerosol Optical Depth from Four Solar Radiometers during the Fall 1997 ARM Intensive Observation Period,” Geophy. Res. Lett., 26, 2725.

Schwartz, SE, CM Benkovitz, G Guo, and Harshvardhan, 2002: “Aerosol Influence on Cloud Microphysics Examined by Satellite Measurements and Chemical Transport Modeling," J. Atmos. Sci., 59, 714-725.

Sheridan, PJ, DJ Delene, and JA Ogren, 2001: "Four years of continuous surface aerosol measurements from the Department of Energy's Atmospheric Radiation Measurement Program Southern Great Plains Cloud and Radiation Testbed site," JGR Atmospheres, 106, 20,735-20,748.

Shupe, MD , T Uttal, SY Matrosov, and AS Frisch, 2001: "Cloud water contents and hydrometeor sizes during the FIRE Arctic Cloud Experiment,” J. Geophys. Res., 106, 15,015.

Stephens, GL, 1996: “How Much Solar Radiation Do Clouds Absorb?” Science, 271, 1131-1136.

Stokes, GM, and SE Schwartz, 1994: "The Atmospheric Radiation Measurement (ARM) Program: Programmatic background and design of the cloud and radiation test bed," Bull. Amer. Meteor. Soc., 75, 1201-1221.

Tao, X, JE Walsh and WL Chapman, 1996: “An assesment of global climate model simulations of arctic air temperatures," J. Clim., 9, 1060-1076.

Thompson, DWJ, and JM Wallace, 1998: "The Arctic Oscillation signature in the wintertime geopotential height and temperature fields," Geophys. Res. Lett., 25, 1297-1300.

Tobin, DC, Revercomb, HE, Knuteson, RO, Feltz, WF, Murcray, FJ, 1999: "Weak water vapor spectral lines in the 8-12 mm atmospheric window," In Proceedings of the Ninth Atmospheric Radiation Measurement (ARM) Science Team Meeting, U.S. Department of Energy.

Trishchenko, A, and Z Li, 1998: "Validation of GOES-7 to a radiation budget for April and July 1994 ARM/IOP using ScaRaB/Meteor-3/7 data," In Proceedings of the Seventh Atmospheric Radiation Measurement (ARM) Science Team Meeting, US Department of Energy.

Turner, DD, 2003: "Microphysical properties of single and mixed-phase arctic clouds derived from AERI observations," In Proceedings of the Thirteenth Atmospheric Radiation (ARM) Science Team Meeting, U.S. Department of Energy. 
Turner, DD, RA Ferrare, and LA Brasseur, 2001: “Average aerosol extinction and water vapor profiles over the Southern Great Plains," Geophys. Res. Lett., 28, 4441-4444.

Turner, DD, BM Lesht, SA Clough, JC Liljegren, HE Revercomb, and DC Tobin, 2003a: "Dry bias and variability in Vaisala RS80-H Radiosondes: The ARM experience," J. Atmos. and Ocean. Tech., 20, 117 132.

Turner, DD, SA Ackerman, BA Baum, P Yang, and HE Revercomb, 2003b: "Cloud phase determination using ground-based AERI observations at SHEBA,” J. App. Meteor., 42, 701-715.

Valero, FPJ, RD Cess, M Zhang, SK Pope, A Bucholtz, B Bush, and J Vitko, 1997: “Absorption of Solar Radiation by Clouds: Interpretations of Collocated Aircraft Measurement," J. Geophys. Res., 104:

$29,917-29,927$.

Vorosmarty, C, L Hinzman, B Peterson, D Bromwich, L Hamilton, J Morison, V Romanovsky, M Sturm, and R Webb, 2002: "Arctic-CHAMP: A program to study Arctic hydrology and its role in global climate," EOS Trans. AGU, 83, 241,244-245,249.

Walsh, JE, and WL Chapman, 1998: "Arctic cloud-radiation-temperature associations in observational data and observational reanalyses," J. Clim., 11, 3030-3045.

Walsh, J and RG Crane, 1992: “A comparison of GCM simulations of arctic climate," Geophys. Res. Lett., 19, 29-32.

Wang, Z, and K Sassen, 2002a: "Cirrus cloud microphysical property retrieval using lidar and radar measurements: I. Algorithm description and comparison with in situ data,” J. Appl. Meteor., 41, 218-229.

Wang, Z, and K Sassen, 2002b: "Cirrus cloud microphysical property retrieval using lidar and radar measurements: II. Midlatitude cirrus microphysical and radiative properties," J. Atmos. Sci., 59, 22912302.

Webb, M, C Senior, S Bony, and JJ Morcrette, 2001: "Combining ERBE and ISCCP data to assess clouds in the Hadley Centre, ECMWF and LMD atmospheric climate models," Clim. Dyn., 17, 905-922.

Xie, SC, RT Cederwall, K -M Xu, P Bechtold, DG Cripe, SJ Ghan, AD Del Genio, SJ Ghan, D Gregory, JJ Hack, SF Iacobellis, SA Klein, SK Krueger, U Lohmann, JC Petch, DA Randall, LD Rotstayn, JC Somerville, YC Sud, K von Salzen, GK Walker, A Wolf, JJ Yio, G Zhang, and M -H Zhang, 2002: "Intercomparison and Evaluation of Cumulus Parameterizations under Summertime Midlatitude Continental Conditions," Q.J.R. Meteorol. Soc., 128, 1095.

Xie, S, RT Cederwall, M Zhang, and JJ Yio, 2003: "Comparison of SCM and CSRM forcing data derived from the ECMWF model and from objective analysis at the ARM SGP site," J. Geophys. Res., 108, doi: 10.1029/2003JD003541. 
Xie, S, M Zhang, JS Boyle, RT Cederwall, GL Potter, and W Lin, 2004: "Impact of a revised convective triggering mechanism on Community Atmosphere Model, Version 2, simulations: Results from shortrange weather forecasts," J. Geophys. Res., 109, D14102, doi:10.1029/2004JD004692.

Xu, K-M, SK Krueger, RT Cederwall, LJ Donner, F Guichard, WW Grabowski, DE Johnson, M Khairoutdinov, JC Petch, DA Randall, CJ Seman, W -K Tao, SC Xie, JJ Yio, M -H Zhang, and D Wang, 2002: "An intercomparison of cloud-resolving models with the ARM summer 1997 IOP data," Quart. J. Roy. Meteor. Soc., 128, 593.

Younkin, K and CN Long, 2004: "Improved correction of IR loss in diffuse shortwave measurements: An ARM value added product,” ARM TR-009, U.S. Department of Energy.

Zender, C, B Bush, S Pope, A Bucholtz, W Collins, J Kiehl, F Valero, and J Vitko, 1997: “Atmospheric Absorption During ARESE," J. Geophys. Res., 102, 29901.

Zhang, GJ, 2002: "Convective quasi-equilibrium in midlatitude continental environment and its effect on convective parameterization,” J. Geophys. Res., 107(D14), 10.1029/2001JD001005.

Zhang, MH, and JL Lin, 1997: "Constrained variational analysis of sounding data based on columnintegrated budgets of mass, heat, moisture and momentum: Approach and application to ARM measurements," J. Atmos. Sci., 54, 1503-1524.

Zhang, MH, WY Lin, and JT Kiehl, 1998: "Bias of atmospheric shortwave absorption in the NCAR CCM2 and CCM3: Comparison with monthly ERBE/GEBA measurements," J. Geophys. Res., 103, 8919-8925.

Zhang, MH, JL Lin, RT Cederwall, JJ Yio, and SC Xie, 2001: “Objective analysis of the ARM IOP data: method and sensitivity," Mon. Wea. Rev., 129, 295-311.

Zhang, M, W Lin, CS Bretherton, JJ Hack, and PJ Rasch, 2003: “A modified formulation of fractional stratiform condensation rate in the NCAR Community Atmospheric Model (CAM2)," J. Geophys. Res., 108, 4035, doi:10.1029/2002JD002523.

Zhang, Y, RC Easter, SJ Ghan, and H Abdul-Razzak, 2002: "Impact of aerosol size representation on modeling aerosol-cloud interactions,” J. Geophys. Res., 107, 4558, doi: 10.1029/2001JD001549. 